\title{
3D-Printed Stationary Phases with Ordered Morphology: State of the Art and Future Development in Liquid Chromatography
}

\author{
Christopher Salmean ${ }^{1}\left[\right.$ : Simone Dimartino $^{1}$ (i)
}

Received: 14 September 2018 / Revised: 30 November 2018 / Accepted: 4 December 2018 / Published online: 14 December 2018

(c) The Author(s) 2018

\begin{abstract}
Stationary phases with precisely ordered morphology have the potential to drastically improve the performance of chromatographic operations, both in the analytical and in the preparative/industrial fields. The recent wave of additive manufacturing, aka 3D printing, gives the unprecedented ability to fabricate such stationary phases and to experimentally prove the theoretical principles of ordered chromatographic beds. The manufacture of highly efficient chromatographic columns is becoming a reality as 3D printers become more affordable and accessible, and their resolution, speed, and material flexibility continue to grow. This brings fresh ideas to the design of chromatographic beds, moving away from stereotypical "packed" beds with spherical particles to bespoke monolithic structures to suit a range of specific applications. This review aims to cover the state of the art of ordered beds for liquid chromatography applications, drawing analogies between the well-established pillar-array columns in two dimensions to their three-dimensional counterparts. The potential use of 3D printing to create entirely new column formats and cartridge designs such as microchip columns will also be discussed. Finally, key opportunities and challenges which remain in the field of 3D-printed chromatography are summarised, with the hope that 3D printed chromatographic columns will soon become the standard.
\end{abstract}

Keywords 3D printing $\cdot$ Packed bed $\cdot$ Chromatography $\cdot$ Porous media $\cdot$ Packing homogeneity

\section{Introduction}

Packed beds are a critical component in most operations in the process industry, with applications including reaction engineering, e.g., catalysis and fermentations, and separation processes, e.g., absorption, adsorption, and distillation [1]. The pervasive nature of packed beds underscores the widespread implications of improvements in their design, fabrication methods, and process performance. Such considerations are particularly important in the chromatography arena, which is driven by the ongoing search for more efficient columns that can achieve separations at high speeds and high resolutions [2].

Published in the topical collection Rising Stars in Separation Science, as part of Chromatographia's 50th Anniversary Commemorative Issue.

Simone Dimartino

Simone.Dimartino@ed.ac.uk

1 Institute for Bioengineering, School of Engineering, The University of Edinburgh, Edinburgh EH9 3FB, UK
As predicted by Knox, improvements in HPLC efficiency and separation speed have been predominantly driven by decreasing particle size $[3,4]$. However, with the passing of the 2- $\mu \mathrm{m}$ threshold in the past decade [5], researchers are quickly approaching the limit of applicable driving pressure and tolerable frictional heating [6], and research must be applied to find alternative methods to improve separation performance.

One major limitation lies in the slurry-packing methods universally employed to manufacture chromatographic columns, as the resulting lack of precise control over particle shape, size, and position has a deleterious effect on separation efficiency $[7,8]$. Ordered, homogeneous beds have been proposed as a solution to drastically increase chromatographic efficiency without affecting pressure drops and throughput $[9,10]$, and dramatic reductions of the height of a theoretical plate (HETP) have been reported in studies employing experiments and simulations [11-13]. Following this principle, the last decade saw the emergence of two-dimensional columns with perfectly ordered internal morphology [14]. These have been extensively fabricated and tested, experimentally demonstrating the theoretical 
improvements associated with ordered stationary phases [15]. However, the manufacture of three-dimensional porous beds has been impeded by inherent structural strength and reproducibility issues. This has restricted research in threedimensional beds to a range of modelling studies, yielding encouraging results but with limited or no experimental validation $[16,17]$.

The recent explosion of additive manufacturing methods (AM, aka 3D printing) has opened a new paradigm for the microfabrication of precisely ordered three-dimensional packed beds. Its "layer-by-layer" production process enables the creation of difficult designs, including the complex network of channels, voids, and overhangs characteristic of chromatographic stationary phases [18]. 3D printing enables fine control over particle size, shape, position, alignment, and configuration, to create complex structures which were previously impossible to produce. This approach has been pioneered by Fee et al. with the printing of arrays of spherical particles as well as alternative configurations such as parallel channels [19]. 3D printing also presents the opportunity to fabricate ancillary column components such as column cartridges (including walls, flow distributors, and connecting fittings) with alternative formats, e.g., spiral or serpentine [20-22].

This review aims to cover the state of the art in ordered stationary phases for liquid chromatography. The discussion will initially revolve around findings from theory, experiments, and modelling with respect to three main morphological traits that define a chromatographic bed, i.e., (i) bed homogeneity, (ii) particle shape, and (iii) bed configuration. The review will then progress to novel complex formats for chromatography cartridges enabled by the $3 \mathrm{D}$ printing technology. Finally, an overview of the potential opportunities and remaining challenges associated with AM methods will be presented.

This review intends to cover the potential benefits of 3D-printing in conjunction with HPLC, and as such does not intend to discuss AM methods as these are already extensively covered in other, more specific reviews [18, 23-26]. The reader is also directed towards a number of recent reviews on the current state of the art in liquid chromatography [6, 27-29].

\section{Factors Influencing the Performance of Porous Beds}

\section{Homogeneity}

It has been posited by a number of researchers that the majority of the band broadening in a packed column is caused by bed inhomogeneity $[3,30]$. For example, it is well known that the irregularities in the flow paths for the mobile phase are responsible for eddy diffusion [31]. John Knox hypothesised that the eddy diffusion term contributes approximately one-half of the minimum reduced plate height, and therefore, the maximum efficiency of a packed bed can be at least doubled on an ideally homogeneous bed [32]. This implies that a separation carried out on a conventional randomly packed column could be equally achieved using a homogeneous column with much shorter bed height (less than half of its original length), with immediate advantages in terms of pressure drops and pumping requirements. On the other hand, a homogeneous column having the same size as its heterogeneous counterpart will have a larger number of plates (at least double), hence enabling separations with higher resolutions (factor $\geq \sqrt{ } 2$ ). There is a further connotation of John Knox's postulation; as the minimal time needed to reach a desired separation resolution is proportional to the square of plate height, a fully homogeneous column would provide the same resolution in under a quarter of the time of its heterogeneous counterpart [30]. These considerations led Knox to recommend that column manufacturers focus on the homogeneity of their packings as opposed to only reducing particle size [33]. The importance of packing methods is highlighted in a recent work by Schweiger et al., showing that even standardised pre-packed columns can exhibit a column-to-column HETP deviation of around 15\% [34].

Seminal works demonstrating the advantages of ordered stationary phases were carried out in two-dimensional systems as early as 1998, i.e., when high-precision etching allowed the creation of highly homogeneous arrays of pillars [35, 36] (Fig. 1). Although 2D pillar arrays cannot directly mimic the interpore connectivity of a 3D system, Eghbali et al. noted that the plate-height models currently used make no assumptions regarding the dimensionality of the system [15]. Accordingly, an understanding of packed-bed behaviour in two dimensions can offer important insights in three-dimensional systems, e.g., by applying shape factors.

Following this approach, minimum reduced plate heights as low as 1 were reported for the first time by De Malsche et al. in 2007 on a largely homogeneous, $1-\mathrm{cm}$-long 2D pillar array [30]. This group has carried out further work in this direction, exploring a range of variables such as size and shape of pillars [37, 38] (further discussed in "Particle Shape" section), bed and monolith porosities [13, 39], and strategies to introduce chromatographic functionality (e.g., electrochemical anodization [39], in situ deposition [40], or growth methods [41, 42]). Their experimental investigations report two-dimensional columns with reduced plate heights as low as 0.2 and separation impedance on the order of 50 for non-retained analytes [27]. The exact homogeneity of their columns was consistently nominated as the primary reason for such elevated efficiency. 

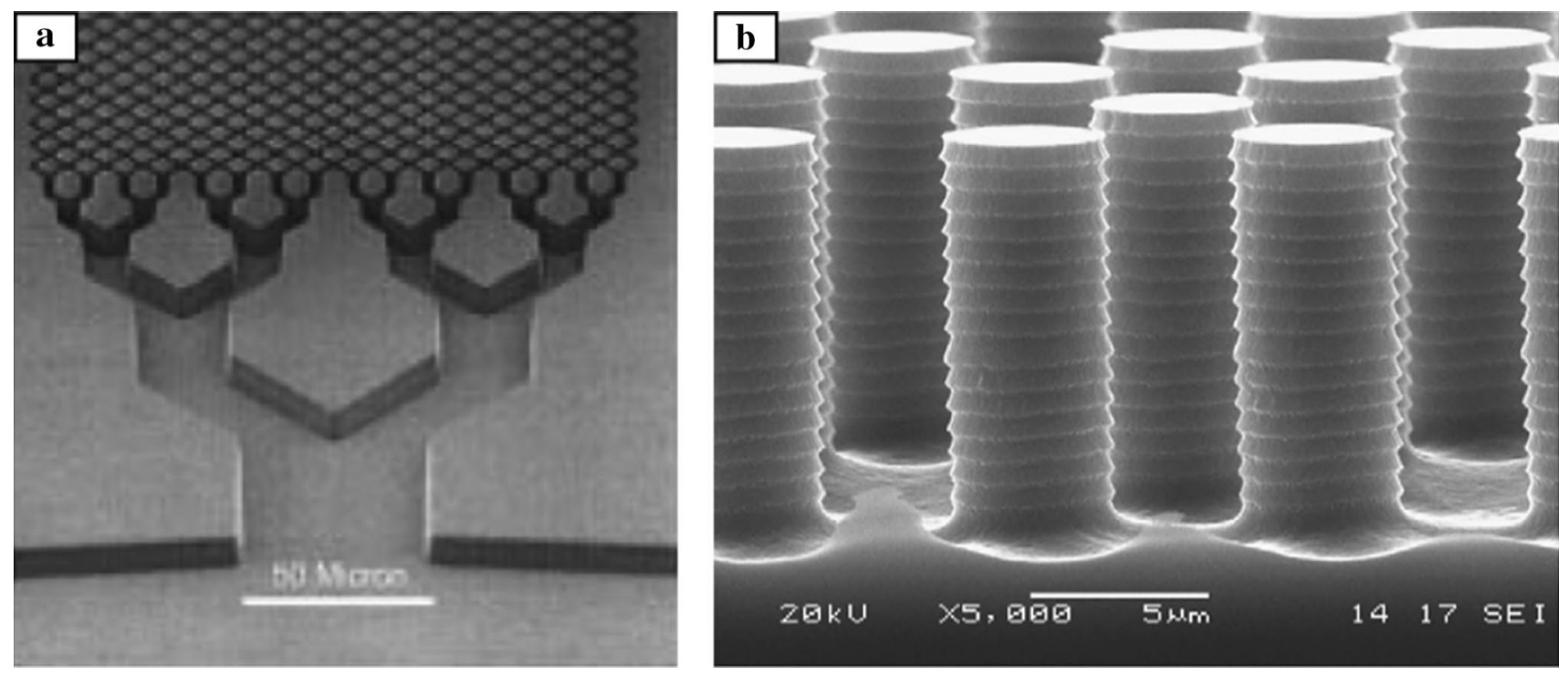

Fig. 1 SEM images of etched pillar arrays. a Published by He et al. in original 1998 proof-of-concept study, reprinted with permission from [35]. Copyright (1998) American Chemical Society. b Produced

The importance of bed homogeneity in pillar-array columns was recognised as early as 2005 in a modelling study by Billen and colleagues [43]. Pillar arrays were considered, with increased degrees of heterogeneity in both the size and positioning of the cylindrical pillars, and the column efficiency in terms of plate height was estimated. The researchers noted that stationary-phase heterogeneity causes the formation of preferential flow paths, giving rise to a large increase in band broadening. This conclusion was further experimentally proven in a 2009 study by Eghbali et al. [15]. Van Deemter curves for pillar-array columns with different degrees of heterogeneity showed an increase of $209 \%$ and $43 \%$ in the $\mathrm{A}$ and $\mathrm{C}$ terms, respectively, as column heterogeneity was amplified.

Two-dimensional pillar-array columns are produced in microchip formats [44], mainly due to limitations in the build size of the fabrication techniques employed, thus preventing the production of upscaled columns that could be employed in the bioprocessing industry. Accordingly, interest in these devices remains confined to the analytical sciences, trending towards the creation of long (over $3 \mathrm{~m}$ ) and very efficient (over 1-million plates) capillary columns [40].

Although far more homogeneous than any packed beds produced to date, the $2 \mathrm{D}$ pillar arrays are still subject to small imperfections due to sidewall effects [45], race track effects [46] and artefacts from the etching process [47].

The effects of inhomogeneities in three-dimensional columns were studied in detail after the advent of superior imaging and analytical techniques in the early 1990s. In a 1993 study, Schisla et al. studied a bundle of parallel capillaries with Gaussian distribution of diameters both using Bosch etching process. Reprinted with permission from Billen and Desmet [10]

experimentally and through simulations. It was demonstrated that, for parallel capillaries, even $1 \%$ standard deviation in the diameter can cause a tenfold increase in HETP [48]. Schisla's polydispersity theory was further developed by Gzil et al. in 2003; using computer simulations, the researchers concluded that redistribution of the fluid flow at regular intervals could effectively eliminate the deleterious effect from non-uniform channels (Fig. 2) [49].

In an effort to interpret band broadening as a quantitative function of bed heterogeneity, Schure and Maier simulated monodisperse packed beds and measured the loss of efficiency as defects were introduced by removing a certain fraction of particles from the bed [16]. It was found that removing just $6 \%$ of particles from a bed caused around a 33\% decrease in column efficiency. The authors argue that the formation of preferential flow paths due to packing defects has a deleterious influence on column performance, and acknowledges that it is impossible to obtain a defect-free packing through use of the traditional slurry-packing methods. The group of Wirth et al. overcame this phenomenon, demonstrating experimentally that submicrometer spherical silica particles tend to spontaneously self-assemble, which lead to the formation of highly ordered packings, even at the periphery of the capillary (Fig. 3) [50]. In addition, columns packed with sub- $\mu \mathrm{m}$ particles contain interstitial channels narrower than $100 \mathrm{~nm}$, leading to slip flow (non-zero fluid velocity at the boundary with the particles) and thus narrower trans-column velocity distributions [51-53]. The increase in both packing order and flow homogeneity was thus associated with decreased band broadening and improved 
Fig. 2 Schematic view of a conceptual parallel plate column which has been optimised using simulation to minimise Schisla's polydispersity effect, printed with permission from Gzil et al. [49]

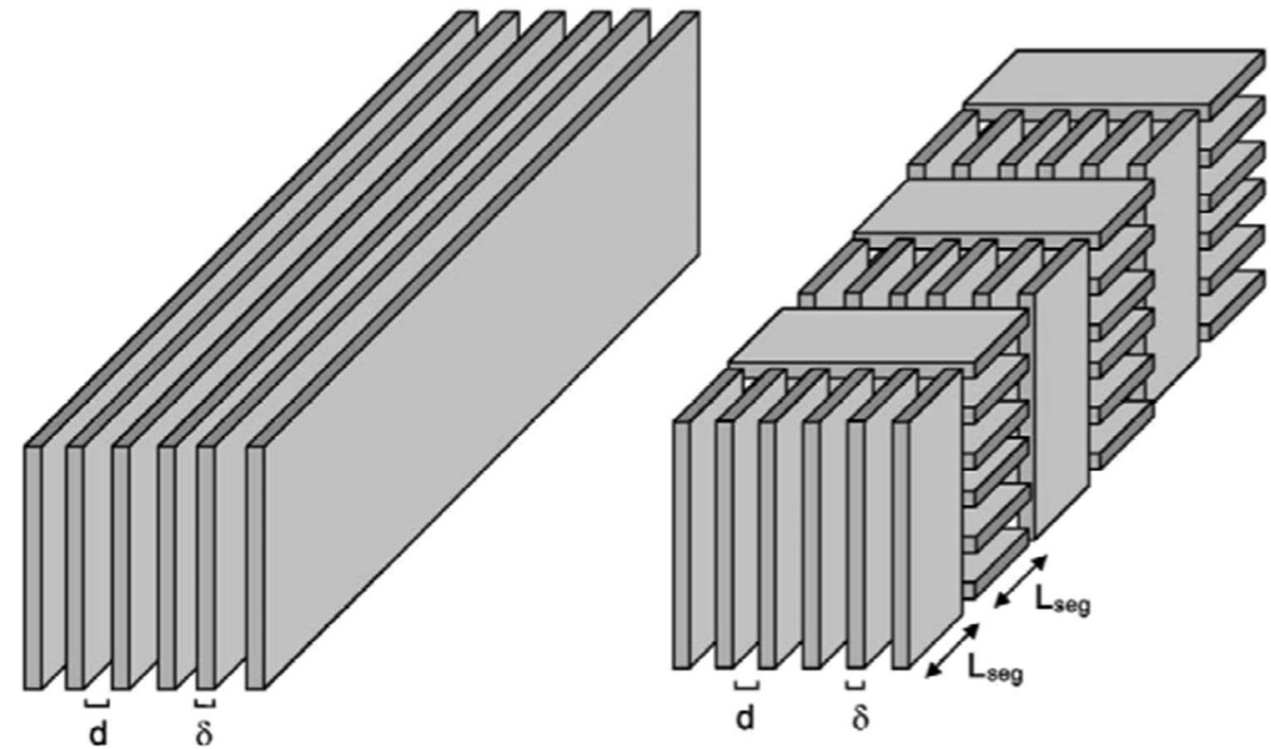

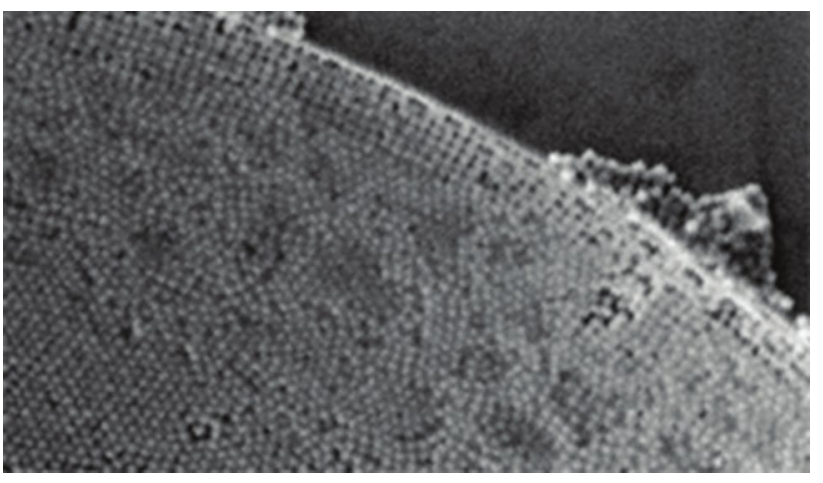

Fig. 3 SEM image of uniformly packed silica nanoparticles at capillary edge. Reprinted with permission from [51]

chromatographic performance, with an impressive reduced plate height of 0.7 [50].

Schenker et al. developed a different method to determine and quantify microstructural heterogeneity through the use of the Voronoi tessellation [54]. This method deconstructs the bed volume into a number of three-dimensional cells, each defined by the location of a particle in the bed and the surrounding empty volume. The distribution of the volumes of the Voronoi cells enables quantitative analysis of the packing morphology in terms of both local packing density and disorder at the same time (rather than considering these two aspects separately, e.g., through the use of bed porosity and velocity distribution, respectively). Khirevich et al. successfully employed the volume distribution of the Voronoi tessellation to accurately and quantitatively predict the observed eddy dispersion [55].

Column walls represent another source of bed inhomogeneity. During column packing, the particles endure intense friction near the wall and are partly crushed or otherwise broken [56-58]. The presence of the column walls also constrains the spatial distribution of the particles, resulting in additional non-uniformities in the radial direction $[59,60]$. In particular, the particles close to the walls tend to create localised regions with higher porosity than the bed average, thus leading to the formation of preferential flow paths in these regions [61]. Numerical simulations demonstrated that wall effects increase axial dispersion, thus reducing separation quality [62]. This concept was reinforced by Reising et al. who used focused ion-beam scanning electron microscopy (FIB-SEM) to reconstruct a commercial analytical column in high resolution; radial structural heterogeneities were clearly observed, and simulations confirmed that fluid velocity, consequently, varied radially within the column [63]. Furthermore, the authors characterised the column as a number of radially resolved packing regimes; an assertion confirmed in a recent modelling study by Gritti [64]. The inherent radial heterogeneity of traditionally packed columns was further discussed by Bruns et al. and Aggarwal et al. who concluded that the causes of the observed trans-column heterogeneity are still speculative $[65,66]$.

Vervoort and colleagues approached this issue in 2D chromatography units, with the design of columns exhibiting minimised wall effects. In particular, they attempted to achieve a uniform flow resistance across the entire column cross section by varying the size of the channels adjacent to the sidewalls [67]. While this approach is theoretically sound, it is extremely sensitive to variations in channel size, e.g., due to fabrication defects. A slightly different approach was proposed by Vangelooven et al. who embedded halfpillars into the walls of a pillar-array column (Fig. 4). The researchers observed that the embedded particles had an increased flow resistance, and hence, the sidewall channels could be widened [61]. Although this solution is also 

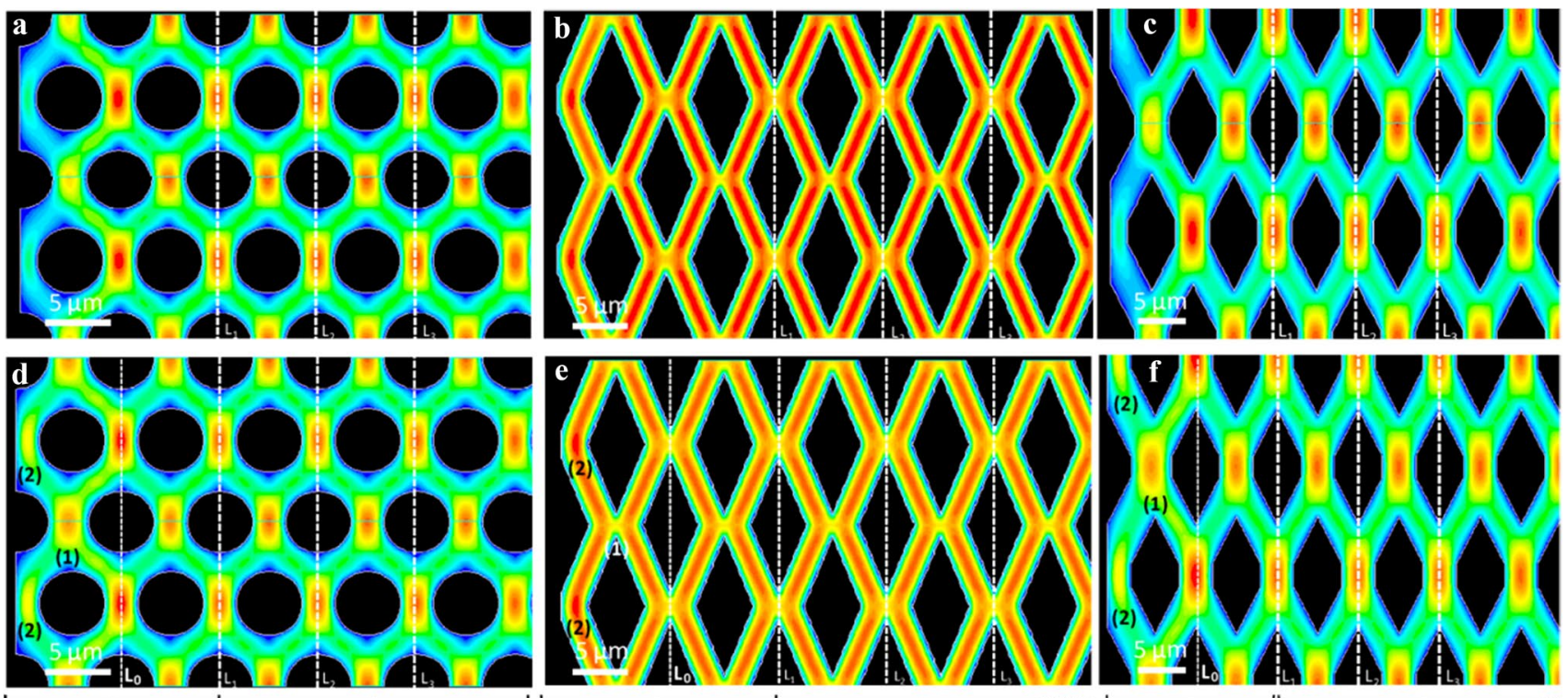

Region A

Region B

$\operatorname{Region} A$

Region B

$\operatorname{Region} \mathrm{A}$

Region B

Fig. 4 Velocity fields showing the use of embedded particles to alleviate sidewall effect in pillar arrays. Note the similarity between the velocity fields next to the sidewalls and inside the pillar array, espe-

extremely sensitive to the precise placement of the wallembedded pillars and nearby channel dimensions, Op De Beeck et al. found that this sensitivity can be decreased through design of radially elongated pillars as the sidewall makes up a relatively smaller portion of the flow paths [30, 40].

Particle-size distribution (PSD) is yet another obvious cause of column inhomogeneity, but its role and how it affects column efficiency is still open for debate. For example, Horváth and colleagues employed a mathematical framework to determine the HETP for columns with different PSDs and for different analytes, and clearly demonstrated that wider size distributions cause higher bed heterogeneity and a decreased column performance [12]. On the other hand, Daneyko et al. employed the Lattice Boltzmann modelling method to simulate the hydrodynamic and chromatographic performance of columns packed with particles having realistic (experimentally derived) PSD [17]. Their results indicate that, while PSD generally affects the HETP, size distributions commonly encountered in commercial chromatography resins are small enough not to produce any noticeable influence on both hydrodynamic dispersion and permeability. Rather than PSD, they point at overall bed homogeneity as the most important parameter for high performance columns, i.e., the key role of the packing process to obtain well-packed columns. Liekens et al. took an experimental approach to the PSD problem, and deliberately packed columns with particles having broad size distributions. Tests were carried out using a commercial batch of cially after tuning the outer pore diameters as shown in the bottom images. Reprinted with permission from [61]

monodisperse $1.9 \mu \mathrm{m}$ analytical particles mixed with $25 \%$, $50 \%$, and $75 \%$ (weight percent) of larger $(3 \mu \mathrm{m}$ and $5 \mu \mathrm{m}$ ) particles. In all the cases, the HETP increased as the PSD was broadened, with particularly detrimental results for the columns spiked with $50 \mathrm{wt} \%$ or $75 \mathrm{wt} \%$ of larger particles. The drop in chromatographic performance was attributed to the settling of the small $1.9 \mu \mathrm{m}$ particles within the channels formed by the large particles, therefore, producing beds with reduced homogeneity as well as lower external porosity [68].

Other stationary phases employed in chromatography include monoliths [69], membranes [70], and fibres [71], which all share the main advantages of higher permeability and mass transport rates over the conventional particles. To date, only monoliths have gained a significant traction as competitors to packed columns in the analytical and preparative chromatography arena. Their porous structure is composed of a complex network of macropores whose size and shape are dictated by the conditions employed during their manufacture. On one hand, this gives the flexibility to prepare monoliths having different skeleton and pore sizes, thus creating materials with reduced flow resistance (i.e., large pores) [72] and increased column performance (i.e., small skeleton size, in line with the use of smaller particles in traditional chromatography) [13, 73-75]. On the other hand, monoliths can be afflicted with structural imperfections leading to preferential flow paths and channelling [76]. Monolithic columns also commonly exhibit trans-column heterogeneities caused by the formation of temperature and concentration gradients during their production as the 
exothermic polymerisation reactions progress [74, 77, 78]. Once more, this unavoidably leads to a random configuration of pores and channels running through the column, as opposed to ideal regular patterns [79]. The development of monolithic columns is another emerging branch of chromatographic research which could be greatly complemented by $3 \mathrm{D}$ printing. In packed beds, the magnitude of the flow through a pore is dictated by the size of the stationary-phase particle (the domain size), with smaller particle sizes defining smaller pores and, therefore, higher flow resistance. Contrastingly, the macropores of a monolithic column can be kept at a near-constant size, while the characteristic skeleton size is varied within practical limits, as shown in Fig. 5 [76].

To describe and model the flow behaviour of real monolithic columns, it is customary to simplify their complex porous morphology into regular networks of channels. In 2004, Vervoort and colleagues represented the monolithic skeleton as tetrahedral unit cells periodically repeating in the three-dimensional space, allowing the simulation of an infinitely extending homogeneous column (Fig. 5) [80]. In a follow-up study, they concluded that the band broadening due to the A-term was around one order of magnitude smaller for the ordered monolith than that obtained in a real, disordered silica monolith, while the $\mathrm{B}$ and $\mathrm{C}$ terms were around their expected values [81]. In 2006, Gzil and colleagues investigated the effects of monolith heterogeneity, porosity, and domain size on HETP, and concluded that the columns become less efficient as their disorder is increased. More recently, Jungreuthmayer proposed modelling the porous morphology of monoliths using channels with alternating wide and narrow diameter [79]. While this model is appropriate in describing the pressure drops characteristics of the experimental monolith, its extension to describe the retention behaviour of solutes has not been discussed.

An expedient to create perfectly homogeneous columns was proposed by Fee et al. who employed 3D printing to create ordered stationary phases composed of monodisperse spherical particles in a simple cubic arrangement, as well as structures containing monodisperse parallel straight or herringbone channels (Fig. 6) [19]. Residence-time distribution experiments revealed that these stationary phases were almost exact replicas of the source digital models. They did note that the particles were slightly irregular on the micron scale due to lack of control over factors such as the printer's resolution limits, venting characteristics of the printer's chamber, forces such as surface tension, and defects during the deposition of the printed material. However, these drawbacks only represent the inherent crudity of the developing 3D printing technology, which will become gradually less significant as printer performance improves. This work also highlighted the opportunity to circumvent wall constraints by effectively embedding the particles into the column walls, as well as minimising radial homogeneities in the flow by appropriate design of the flow distributor and collector at the column entrance and outlet. The work of Fee and colleagues most importantly demonstrates the ability to design homogeneous beds using computer software, and their reproducible fabrication through $3 \mathrm{D}$ printing. This method, albeit currently limited by its resolution, speed, and available materials (to name a few factors), represents a new and feasible approach to the fabrication of packed beds. Stationary phases with new geometries and configurations can be conceived, designed, printed, and tested, ultimately advancing the investigation of fundamental principles and phenomena in chromatography as well as the determination of optimal column designs for industrial applications.

\section{Particle Shape}

It is widely held that spherical particles are the best shape to pack chromatography columns. This concept is so prevalent that is often taken for granted as a true statement. It
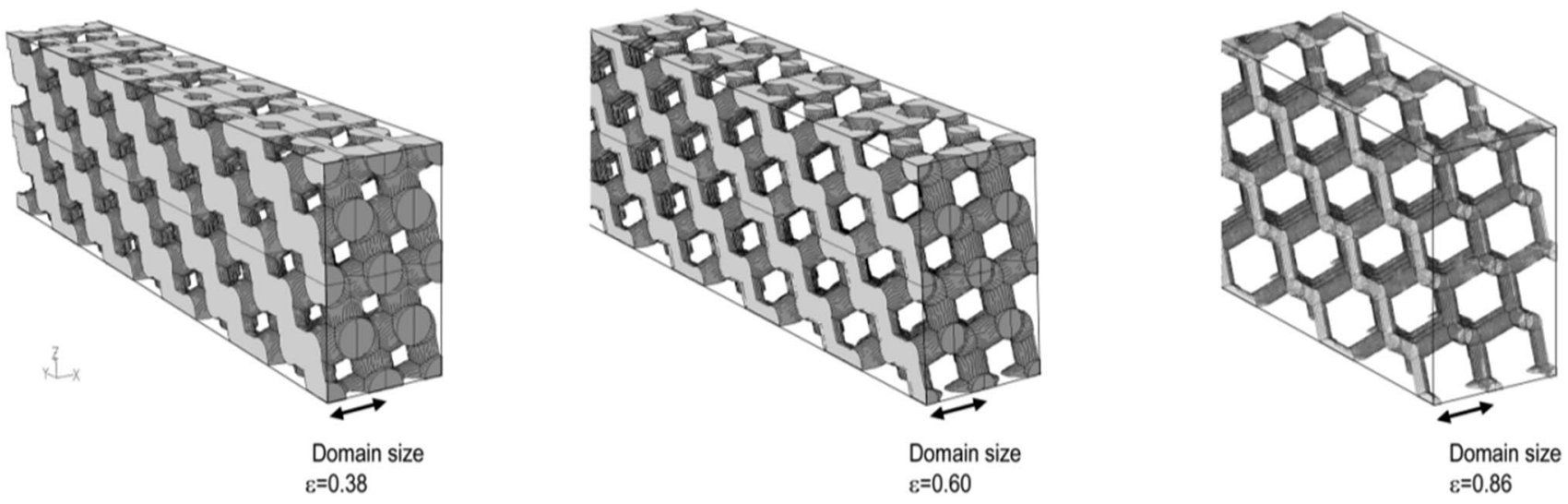

Fig. 5 Schematic diagram shows the maintenance of domain size, while monolithic skeleton size and subsequent porosity are varied. Published with permission from Gzil et al. [13] 

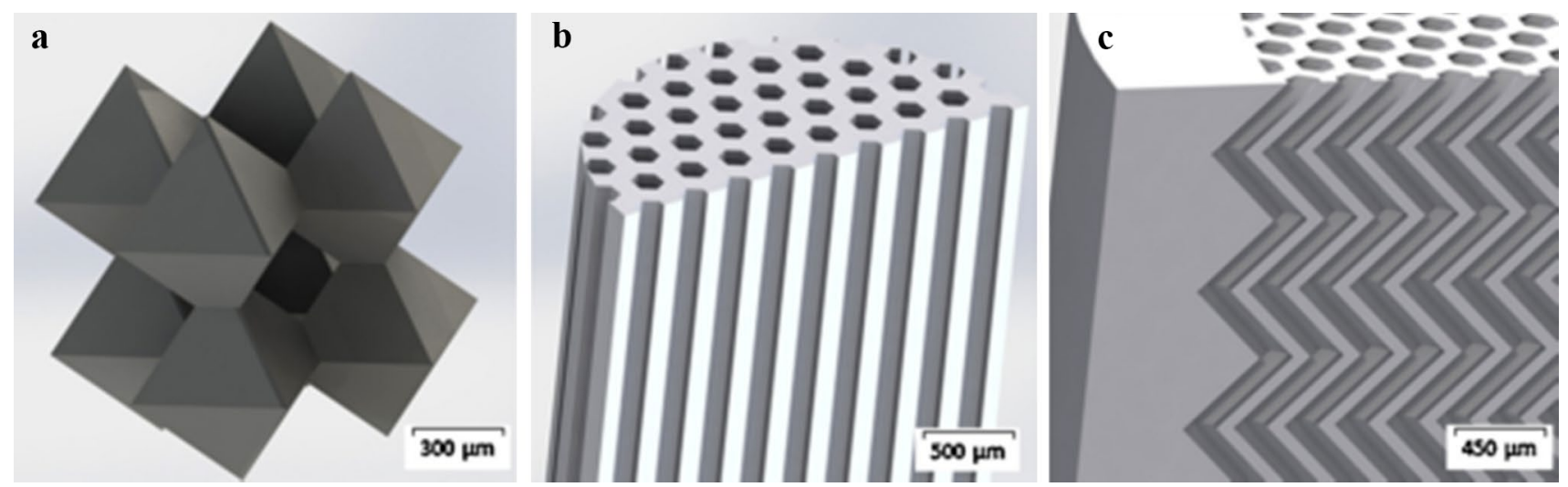

Fig. 6 Geometric designs of 3D-printed bed packings: a simple cubic beads, $\mathbf{b}$ straight channels, and $\mathbf{c}$ herringbone channel. Reprinted with permission from [19]

is true that the shift from irregular particles (e.g., crushed porous glass or silica) to spherical particles represented a major milestone in chromatography [82]. However, this conclusion is only valid for columns packed using the conventional slurry-based procedures, which unavoidably produces a random bed of particles regardless of their original shape. In 2009, Lottes et al. employed X-ray tomography to show that intra-column homogeneity in a slurry-packed bed is better achieved using regular, spherical particles as opposed to irregular particles [83]. Given that slurry packing has been and still is the standard in column chromatography, resin manufacturers have focused on production methods that deliver the most spherical particles possible and with as homogeneous size as possible (see discussion on particlesize distribution in "Homogeneity" section).

Investigations of particle shape in two-dimensional column formats can, again, offer some useful insights that can be qualitatively transferred into three dimensions. The quest for the ideal pillar shape in 2D columns has been carried out mostly though Computational Fluid Dynamics (CFD) methods, as CFD gives the designer the freedom to create pillar arrays with low time and financial burdens. Following this approach, De Smet et al. and Gzil et al. investigated the performance of equilaterally staggered arrays of cylindrical, hexagonal, oval-shaped, and diamond-shaped pillars (Fig. 7) [38, 84]. It was found that HETP and separation impedance significantly decreased when axially elongated diamond-shaped pillars were considered. The researchers concluded that infinitely elongated pillars, effectively a series of parallel plates, would provide a theoretically ideal column morphology with no polydispersity issues. While this is theoretically true, small irregularities in the channel dimensions of a real column would be detrimental to the performance of the whole column, hence the need to split
Fig. 7 Calculated velocity fields for a cylindrical, b hexagonal, and $\mathbf{c}$ elongated diamondshaped pillars with equal crosssectional area. Streamline shade indicates local velocity, with darkest representing highest velocity. Reprinted with permission from [84]

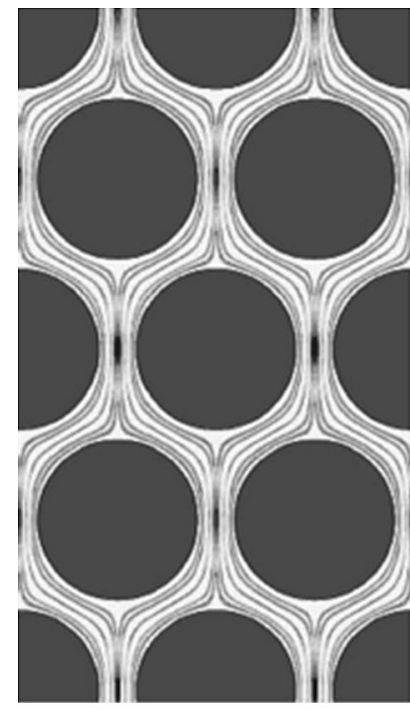

a

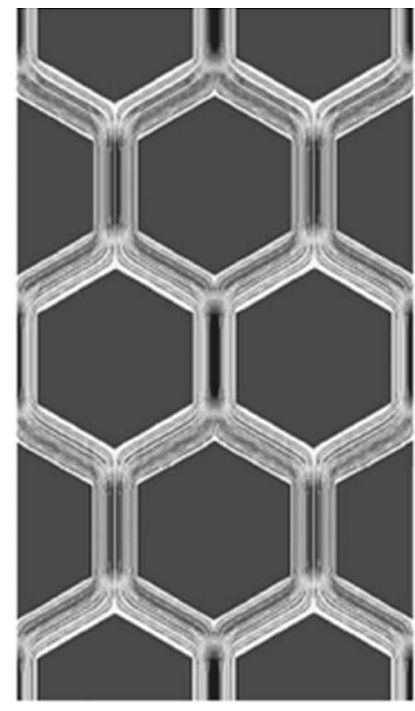

b

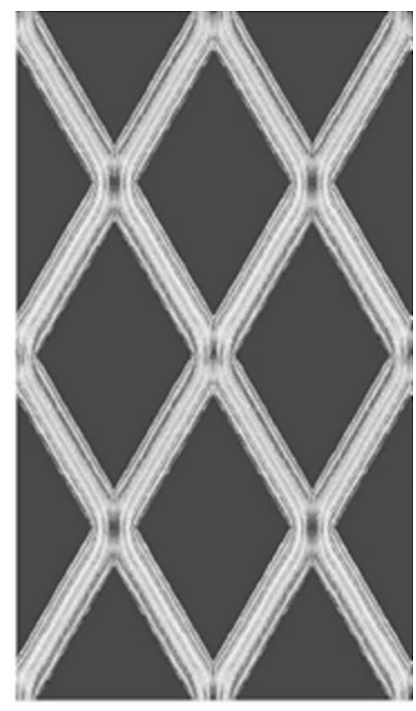

c 
and re-connect the fluid flow at regular intervals, e.g., using diamond-shaped pillars [49]. De Smet and co-workers also analysed the effect of external porosity in conjunction with pillar shape and found that, for all porosities considered, the diamond-shaped pillars gave the smallest HETP and fastest separation [85]. They theorised that elongated pillars cause less flow disturbance in their wake, reducing eddies, and, consequently, A-term band broadening. To date, diamondshaped pillars are still the benchmark in 2D chromatographic chips $[86,87]$.

The pillar shape can affect more than just A-term band broadening: by physical experimentation, Op de Beeck et al. found that orthogonally elongating the pillars of a $2 \mathrm{D}$ bed could produce up to a sixfold gain in non-retained column HETP [37]. This effect was attributed to the decrease in axial diffusion caused by severe inhibition of fluid flow in the longitudinal direction and subsequent promotion of anisotropy in this direction.

2D columns are generally fabricated with individual pillars that do not contact each other. This condition cannot be met in a 3D structure, where their particle elements must be in mutual contact to ensure structural stability of the stationary phase. In practice, the concept of "packing" is lost in an ideally homogeneous 3D chromatography column, with an interconnected structure effectively having monolithic properties. For example, a homogeneous column composed of diamond-shaped beads is only structurally possible if these are uniformly arranged and slightly overlapping, as shown in Fig. 8, rather than just equilaterally staggered [88].

The effect of particle shape in three-dimensional columns is a topic with very little consideration in the literature. In 2010, Yang and colleagues studied the heat-transfer characteristics of ordered beds composed of axially elongated ellipsoids with different packing configurations and morphology. Compared to homogeneous beds of spherical particles, the axially elongated ellipsoids showed reduced pressure drops, although the heat-transfer coefficients were similar [89]. Further simulations by Li et al. confirmed the benefits of particle elongation in terms of chromatographic efficiency and pressure drops $[11,90]$, demonstrating that beds composed of axially elongated ellipsoidal particles have improved hydrodynamic characteristics (lower pressure drops) and chromatographic performance (smaller plate height) than their spherical counterparts. The authors attributed this result to the greater uniformity in local velocities and smaller stagnant areas. These findings in 3D columns are consistent with simulations on 2D columns, where axially elongated pillars are routinely employed.

In 2017, Nawada et al. demonstrated the 3D printing of perfectly ordered beds with particles having different shapes, including truncated icosahedra (approximating spheres), tetrahedra, octahedra, and stella octangulae (Fig. 9). For the first time, the use of 3D printing enabled the fabrication of columns with homogeneous packings, i.e., physical columns that could be connected to chromatography equipment and experimentally tested [91]. Interestingly, beds composed of tetrahedral particles are endowed with smaller reduced plate height than those made of spherical particles over a wide range of Pe numbers, a result in line with the use of diamond-shaped pillars in 2D columns. More importantly, this result questions the accepted concept that spherical particles are superior to any other particles shape. While this might be true for random packings, the new landscape of ordered beds presents the opportunity for novel designs for improved columns with homogeneous geometry.

\section{Packing Configuration}

3D structures exhibit a higher degree of conformational freedom than their simpler 2D counterparts. A homogeneous 3D column can be visualised as an array of perfectly duplicated unit cells in all three dimensions [92]. Yet, there is no limit to the complexity of the unit cell, as long as it obeys the basic boundary conditions for periodicity in all dimensions to ensure continuity and homogeneity of the solid phase. It is, therefore, apparent how the investigation of the "ideal"
Fig. 8 Comparison of a nonoverlapping and $\mathbf{b}$ overlaying cuboidal particles in the simple cubic arrangement. Printed with permission from [88]

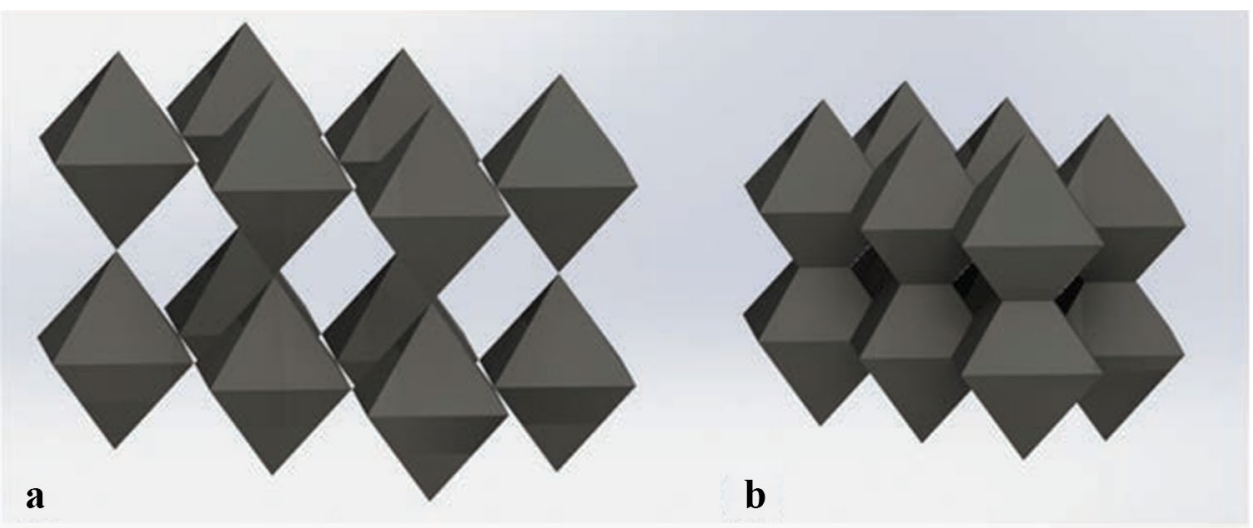



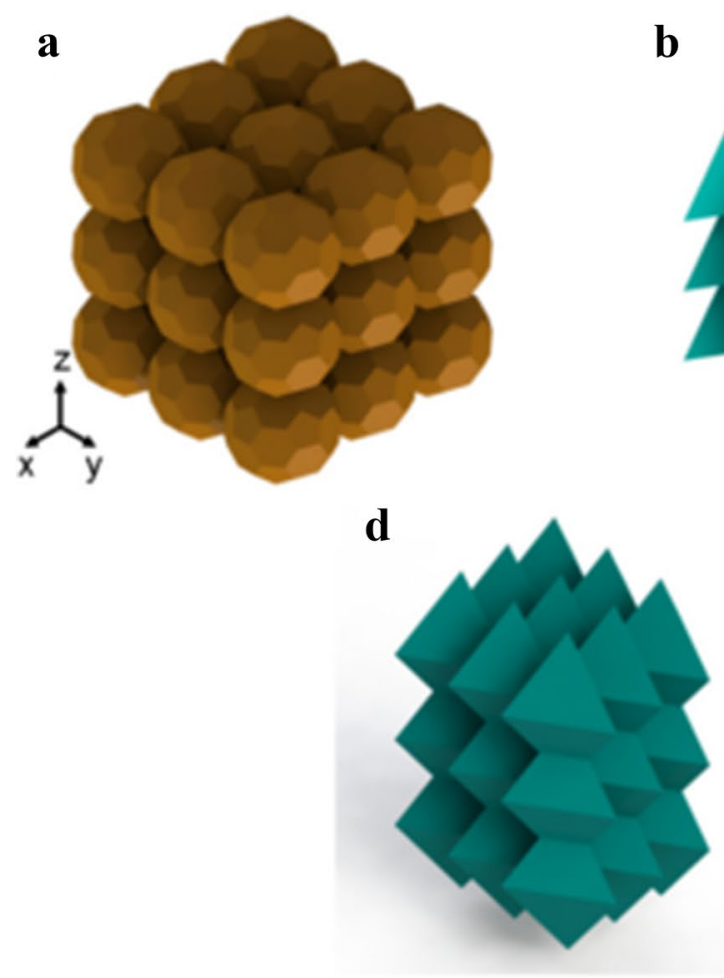
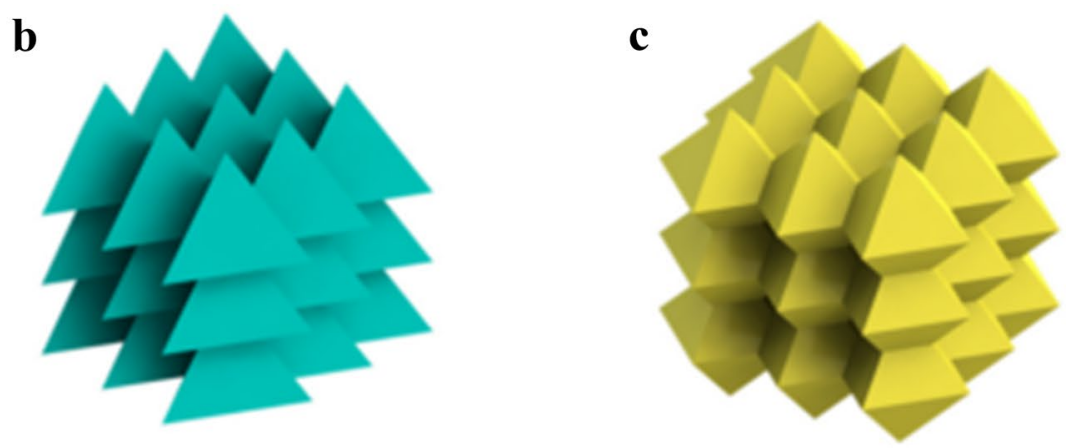

$\mathbf{e}$

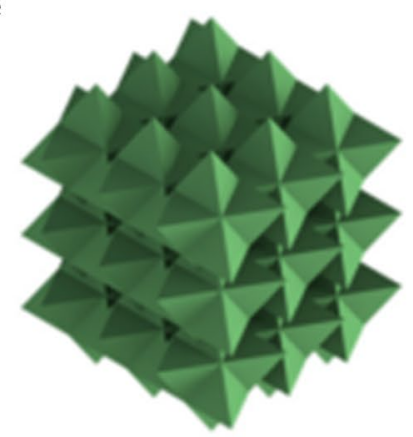

Fig. 9 Visualisation of the bead morphologies 3D printed by Nawada et al.: a spheres, $\mathbf{b}$ tetrahedra, $\mathbf{c}$ octahedra, $\mathbf{d}$ triangular bipyramids, and e stella octangulae. Reprinted with permission from [91]

structure for chromatographic operations exponentially increases in its complexity when moving from 2D to 3D. The first studies on packing configurations started in 2004, when Schure et al. investigated in silico the flow effects of various homogeneous packed beds of spheres in the simple cubic (SC), body-centred cubic (BCC), and face-centred cubic (FCC) arrangements, as well as a randomly packed structure [93]. Their simulations indicate that, in the range of Reynolds numbers commonly used in HPLC operations, the FCC arrangement exhibits lower band broadening than SC, BCC, or randomly packed arrangements (Fig. 10). This result was linked to the distribution of flow velocities in the bed, with FCC characterised by a narrower range of velocities than the other arrangements. In other terms, the flow field in the FCC arrangement enables a relatively uniform velocity profile across the entire bed, a condition close to the theoretical plug flow profile of ideal columns. On the other hand, BCC, SC, and random configurations displayed wider distributions of flow velocity, i.e., increased probability of stagnation zones (low velocity areas) as well as preferential channels (high velocity zones), both of which significantly contribute to A-term band broadening. The presence of preferential channels is particularly obvious in the SC configuration, where unobstructed channel-like paths running down the column are present between the spherical particles (Fig. 11). This work was extended by Li et al. who used the CFD simulations to investigate the chromatographic performance of homogeneous beds of spherical or ellipsoidal particles arranged into SC, BCC, or FCC configurations [90]. In line with the work of Schure et al., they concluded that, regardless of particle shape, FCC packing performs better than the other packing arrangements. Again, the superior efficiency of the FCC configuration was attributed to the more uniform mobile-phase velocity distribution in the bed.

This concept was experimentally demonstrated in the 2017 paper of Nawada et al. where columns containing arrays of spherical particles in the SC, BCC, and FCC configurations were $3 \mathrm{D}$ printed and their plate height measured in non-retained conditions. The experimental results clearly show that the van Deemter curve for the FCC column (showing a very low minimum reduced plate height of 1) sits below that for the BCC and SC arrangements over a range of Pe numbers (Fig. 10) [91]. This conclusion qualitatively matches the prior computational results, with deviations between experiments and simulations credited to experimental errors, flow non-idealities (e.g., due to the 3D printed column distributor and the presence of column walls) and minor deviations or defects in the 3D printed stationary phase.

These studies, however, limited their analysis to arrangements with main axis aligned with the main direction of the flow. A further degree of conformational freedom is represented by the orientation of the ordered 

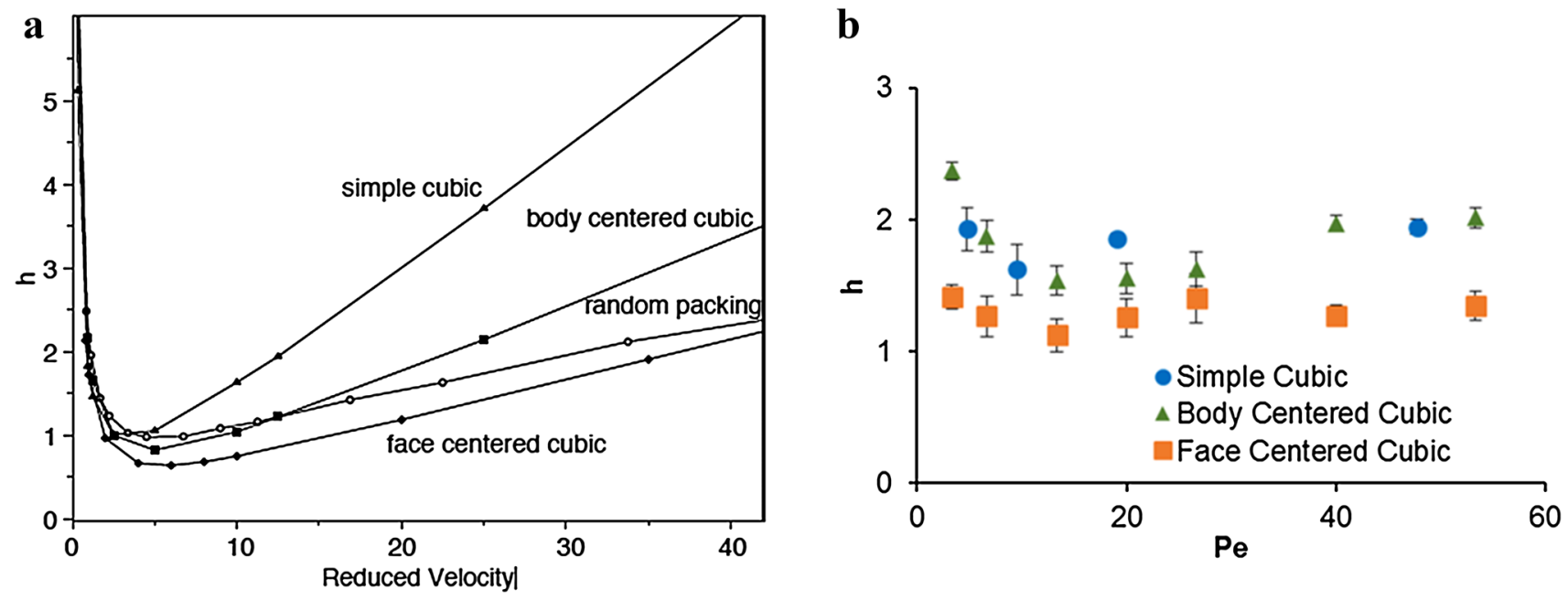

Fig. 10 van Deemter plots for ordered arrays of spherical particles in different arrangements: simple cubic, body-centred cubic, and face-centred cubic. a Simulated results (with permission from Schure et al. [93]) and b experimental results (with permission from Nawada et al. [91])

Fig. 11 Cross section from simulation of flow through SC packing, showing the presence of preferential flow paths and stagnant regions. High local flow velocity is visible along the axial centre and lower velocity around the particles. Adapted with permission from [94]
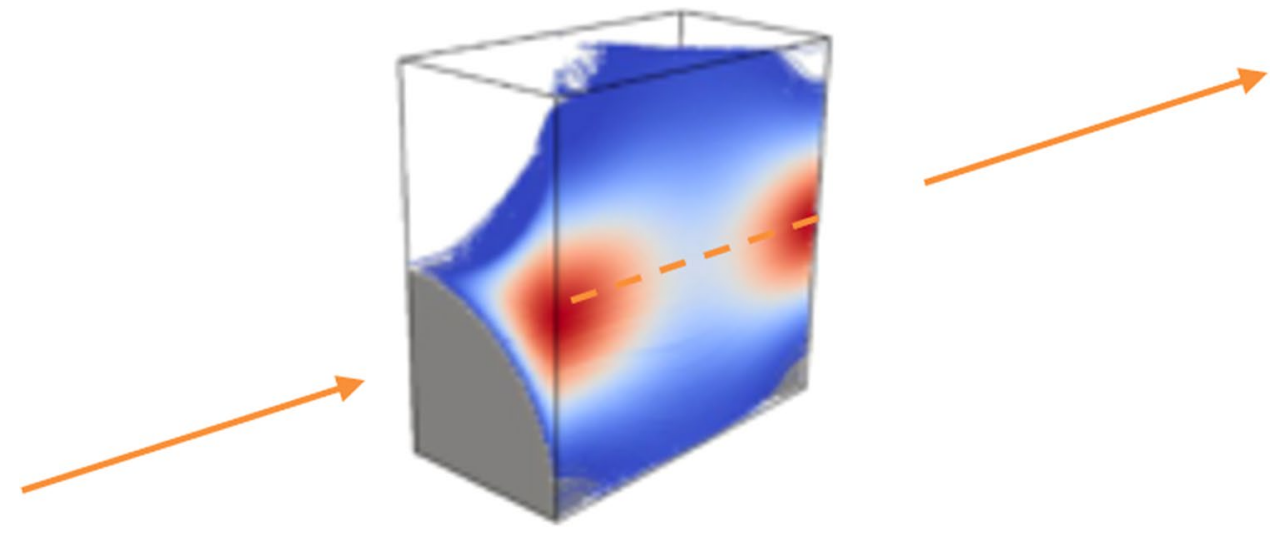

structures with respect to the axial direction of the column. Dolamore et al. considered again SC, BCC, and FCC configurations of spherical particles, but their simulations also comprised a range of bed orientations obtained by rotating the unit cell with respect to the main axis of flow [94]. Interestingly, chromatographic efficiency measured in terms of the reduced plate height was not simply related to packing configuration, but was also highly dependent on its alignment. For example, SC structures in the [111] orientation (relative to a cubic 3D lattice) performed almost as well as FCC in the standard [001] orientation, thus challenging FCC as the most efficient packing configuration. On the other hand, rotation of the FCC arrangement from the very efficient [001] alignment to the [011] direction caused a dramatic increase in plate height, thus producing worse chromatographic performance. It was demonstrated that there is a strong linear relationship between plate height and tortuosity, a descriptor of the degree of turns and interconnections in the bed. Dolamore et al. concluded that arrangements exhibiting higher tortuosity are characterised by higher transverse mixing, which, in turn, reduces inter-channel heterogeneities, promoting homogeneous velocity profiles and thus leading to reduced axial dispersion phenomena and improved column performances. This result, therefore, agrees with Schisla's polydispersity effect.

Another conformational degree of freedom is posed by the $3 \mathrm{D}$ orientation of each particle in the unit cell. While this effect is not of relevance for spherical particles, it might have a reasonably strong influence on beds composed of other particles shapes such as, for example, the well-performing tetrahedral particles discussed previously in "Particle Shape" section. Yet, this option has not been investigated so far, possibly because of the observation that more efficient chromatographic beds are not composed of discrete particles but rather of other geometries such as the bicontinuous and triply periodic minimal surface (TPMS) functions, which are discussed in "Design" section. 


\section{Alternative Column Formats}

Recent developments in proteomics, metabolomics, and the health sciences require advanced chromatographic methods able to deliver extremely high peak capacities in a reasonably short time [95]. Multidimensional separations (e.g., $\mathrm{LC} \times \mathrm{LC}-\mathrm{MS}$ and $\mathrm{LC} \times \mathrm{LC} \times \mathrm{LC}-\mathrm{MS}$ ) [96] and extremely long columns in miniaturised format [97] are the two main approaches currently considered to address this need. Both alternatives can greatly benefit from appropriate design of the column cartridge, making the traditional cylindrical formats relatively obsolete.

Extremely long chromatographic columns can only be manufactured, transported, and employed if they can fit onto a reasonably small area, e.g., a microchip. New column geometries with folded or coiled channels have, therefore, been recently proposed to solve this issue; folded configuration is the most popular solution in pillar-array columns for portable microchip-HPLC [98, 99]. An interesting example is the manufacture, through photolithographic methods, of a 3.1-m-long pillar-array column by De Malsche et al. attaining an efficiency of over 1-million theoretical plates [40].

One challenge in the creation of folded columns is the so-called 'racetrack effect', i.e., the skewing of solute bands caused by non-uniform fluid velocity across the column's turns (Fig. 12a). In the racetrack effect, the solute on the 'outside track' of the turn travels farther than that on the 'inside track', with deleterious effects on column performance [100]. In 2001, Griffiths et al. used numerical simulation to design low-dispersion turns for microchip chromatography applications, concluding that narrowing the turns and thus minimising the difference

$\mathbf{a}$

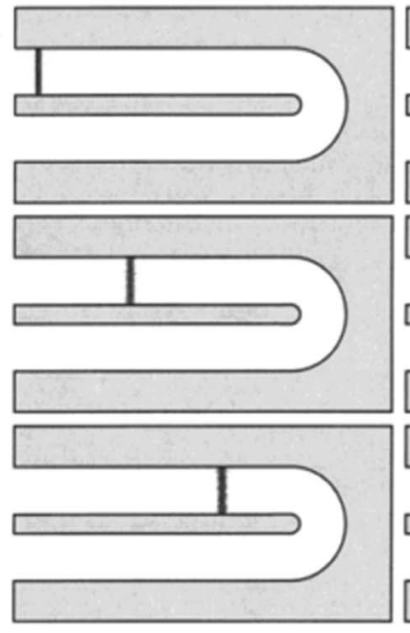

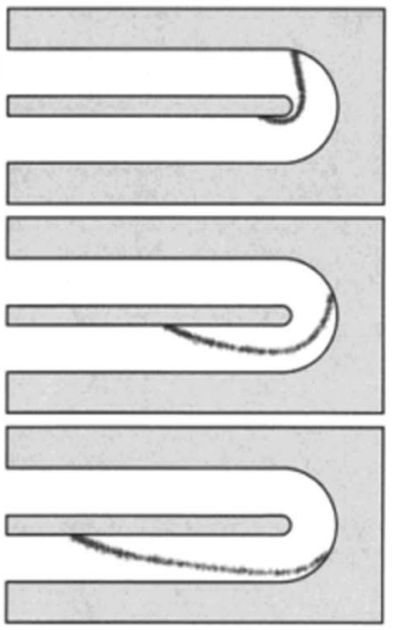

b

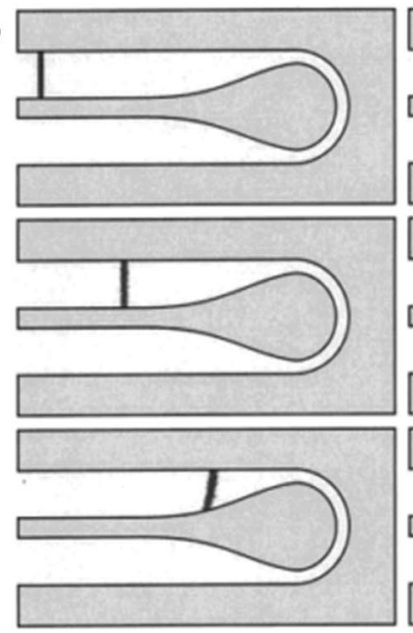

between the inner and outer radii effectively reduce dispersion (Fig. 12b) [101]. The integration of this feature in two-dimensional folded columns has allowed columns to be miniaturised to chip-scale while maintaining extremely low HETP values [40]. Further development of these devices has led to the successful separation of amino acids in just 40-200 s, setting the scene for rapid and easy-touse modular microchip-HPLC in proteomics $[97,99,102]$.

In 2014, Sandron et al. manufactured long $(600 \mathrm{~mm})$ capillary columns with a footprint of just $30 \times 58 \mathrm{~mm}$. The complex column casing, manufactured through $3 \mathrm{D}$ printing, contained a double-handled spiral capillary to fit the column in a coiled configuration. (Fig. 13) [20]. The column was slurry-packed with silica particles and tested for the separation of a mixture of small molecules, but poor packing due to the surface roughness of the column's walls (caused by the $3 \mathrm{D}$ printing technique employed) and the racetrack effect from the curved structure dominated band broadening. In a follow-up study, Gupta et al. polymerised a monolithic stationary phase inside the 3D printed spiral capillary, partly (but elegantly) overcoming the problems associated with the rough column walls and the related packing difficulties [21]. More recently, the same authors empirically attempted to reduce the racetrack effect by testing different 3D-printed column geometries [103]. 2D serpentine, 3D spiral, and 3D serpentine capillary columns of equal length and i.d. were 3D printed and functionalised with a monolithic stationary phase. It was found that the 3D serpentine column exhibited the highest performance, with higher plate height and peak capacity than either of the other designs. The authors suggest that this effect results from improved interactions between channels in the monolith, but the simulation methods employed to reach this conclusion do not seem robust enough to fully support this hypothesis. For example, this

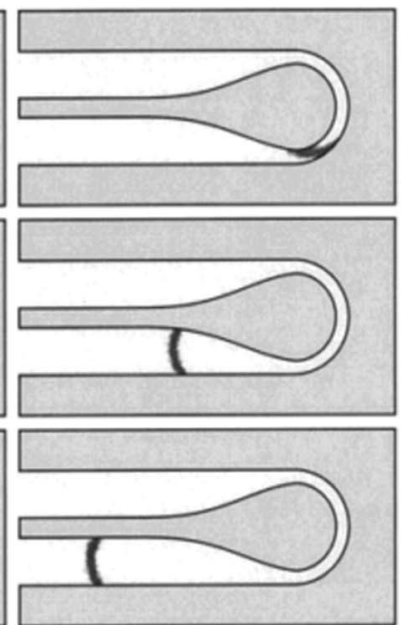

Fig. 12 Numerical simulation showing dispersion due to the racetrack effect across a non-optimised and $\mathbf{b}$ optimised turns. Reprinted with permission from [101]. Copyright (2001) American Chemical Society 

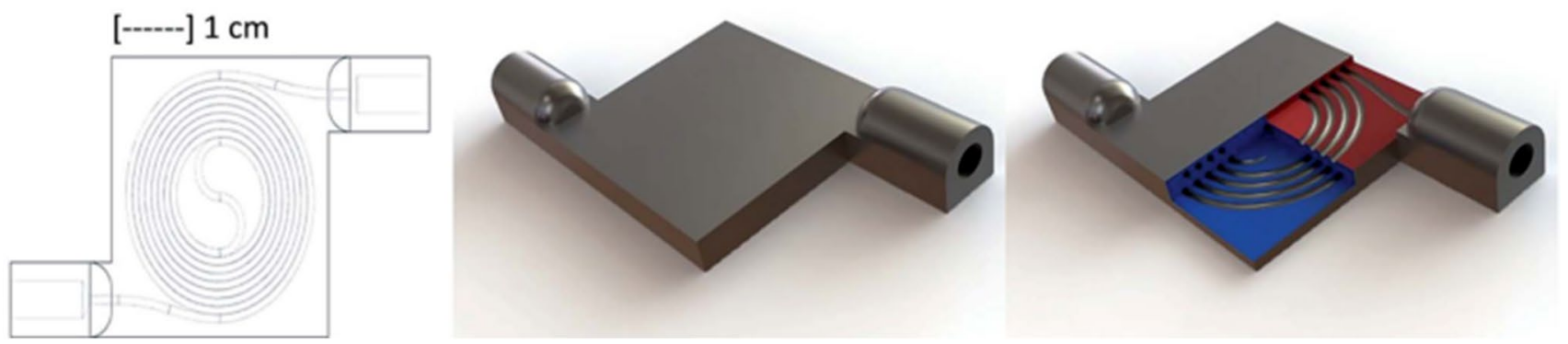

Fig. 13 Rendering of 3D-printed titanium capillary column produced by Sandron et al. Reproduced from [20] with permission from The Royal Society of Chemistry

theory was contradicted in a 2018 study by Gilar et al. in which the authors use simulation and experiments to evaluate the performance of straight packed channels versus a variety of serpentine channels. It was concluded that turns negatively affect 3D LC performance, with a $24 \%$ loss of efficiency observed for an S-shaped $150 \mu \mathrm{m}$ i.d. channel with respect to a straight column. However, it was also observed that tapering the turns and reducing the channel size can alleviate these performance losses [104], in agreement with the studies on two-dimensional pillar-array columns mentioned above.

These new column formats can also help with temperature control, e.g., the minimisation of axial and radial temperature gradients in the column due to frictional heating, preventing any loss of efficiency due to inhomogeneous properties of the analytes [105]. Viscous heating can be alleviated by increasing the thermal conductivity of the column cartridge, allowing more effective heat transfer from the centre to the edges of the column for dissipation. In 2014, Vonk et al. fabricated a titanium-scaffolded structure and polymerised a monolith within the scaffold [75]. They showed that highly conductive column casings can drastically reduce temperature heterogeneity through rapid dissipation of frictional heat. The use of titanium as material with high thermal conductivity was also employed in the capillary columns described by Gupta et al. [20, 21, 103]; this, along with the coiled design of the column cartridge, allowed effective temperature control by positioning Peltier modules below and above the compact chromatographic chip.

The move from single-column chromatography to comprehensive two-dimensional LC represented a massive step change for the separation of complex mixtures. Yet, 2D-LC reaches its analytical limits when challenged to isolate the thousands of components found in typical samples from the "omics" fields [106]. Spatial three-dimensional chromatography ( $\mathrm{LC} \times \mathrm{LC} \times \mathrm{LC})$ is expected to significantly increase peak capacity through the coupling in sequence of three orthogonal (i.e., with differing retention mechanisms and selectivity) chromatographic separations [96]. In 2015,
Wouters et al. designed and developed, for the first time, a spatial 3D-LC device where the three different dimensions were contained in a single microchip (Fig. 14) [107]. The authors demonstrated the potential improvements of their 3D-LC chip in peak capacity and analysis time over 1D-LC and 2D-LC. Yet, its manufacture is inherently complex and delicate, involving the exact stacking of microfluidic modules to ensure appropriate connectivity between the different dimensions. 3D printing has recently been proposed to fabricate 3D-LC chips to achieve ultrahigh peak capacities [108].

\section{Opportunities and Challenges of 3D Printed Chromatography Columns}

It is clear that $3 \mathrm{D}$ printing has the potential to offer numerous solutions to current challenges at the forefront of chromatography. Column performance can be improved at all

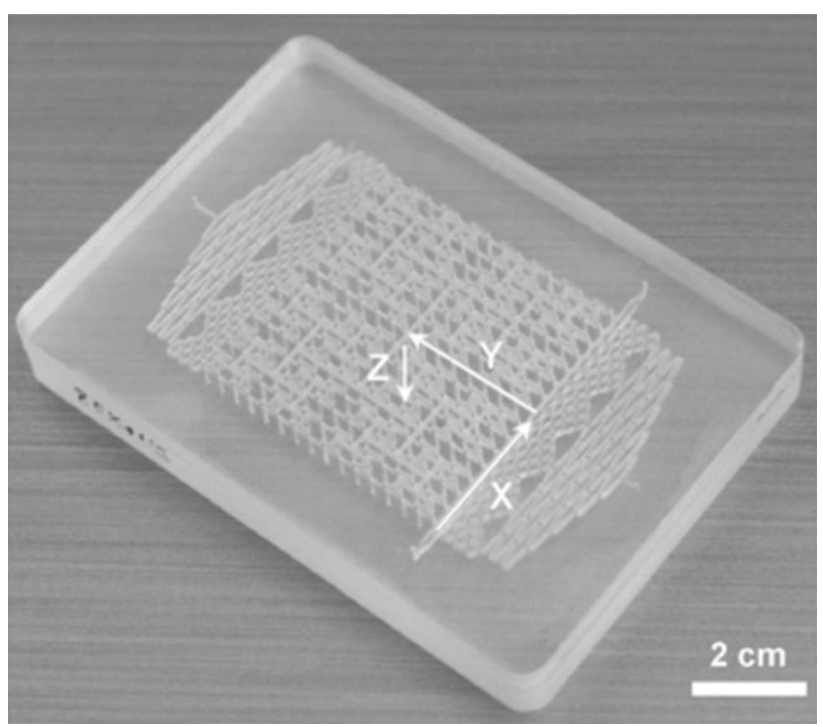

Fig. 14 3D-LC device assembled from stacked fluidic modules, with $X-, Y$-, and $Z$-axes displayed. Reproduced from [107] with permission from The Royal Society of Chemistry 
scales through careful control of the bed morphology, with applications spanning from small columns in the analytical field to large downstream equipment in the biopharma industry. This concept can be extended to the production of bespoke column designs, customised to satisfy specific separation requirements. Indeed, there has recently been interest in the use of 3D printing in chromatographic applications other than LC [109]; for example, planar chromatography $[110,111]$ and gas chromatography $[112,113]$. Another recent development in the field is the investigation of 3D-printed HPLC ancillary elements, such as valves for microflow injection analysis [114], flow distributors [19], detectors [115], and tips for coupling with mass spectrometry (MS) equipment [116].

Effectively, 3D printing could enable the quick prototyping and manufacture of complex bespoke equipment at low cost $[111,117]$, a functionality which is likely to revolutionise analytical and industrial chromatography as specialised equipment is designed on a case-by-case basis [118, 119]. The discussion below presents the current challenges and opportunities in the field, with an aim to advise future research. This review deliberately chose not to cover 3D printing techniques, but the reader is referred to the following reviews for more information on this facet $[18,23,24$, $120,121]$.

\section{Resolution and Speed of 3D Printers}

The capability of AM to produce highly ordered packed beds from CAD models was proven for the first time by Fee et al. [19], but the applications of the technology are still somewhat limited due to the resolution and speed of the printers. This limitation was first observed in the biomedical field, where porous materials were 3D-printed to fabricate cell scaffolds for regenerative medicine [122, 123]. At the time, most researchers were satisfied with features (e.g., strands and channels) of around $300 \mu \mathrm{m}$ diameter, an appropriate size to accommodate the cells and promote vascularisation. While $300 \mu \mathrm{m}$ is in the same order of magnitude of particle sizes used in preparative and industrial chromatography (even though one must note that it sits at the very top of the range), this figure is two orders of magnitude larger than the average size of particles used in the HPLC applications. The need to refine the resolution of 3D printing techniques to match chromatographic requirements is thus apparent.

The $3 \mathrm{D}$ printing arena is highly dynamic and extremely competitive, with continuous improvements in the existing printing methods and new technologies being developed. High-resolution 3D printing technologies exist today, such as, for example, Direct Inkjet Printing (DIP, nominal resolution as low as $10 \mu \mathrm{m})[124,125]$, Projection Micro Stereolithography (P $\mu \mathrm{SL}$, reported nominal resolution 0.6-2 $\mu \mathrm{m})$ [126, 127], and Two Photon Photopolymerization (TPP, nominal resolution 0.1-1 $\mu \mathrm{m}$ ) [128-130]. In 2014, Malinauskas et al. successfully demonstrated the 3D-printing of materials with features as small as $5-\mu \mathrm{m}$ in size [131]. These features were subtractively manufactured on 3D-printed structures by laser ablation, demonstrating how a combined approach could be applied to overcome the resolution limits of additive manufacturing.

Yet, there is major discrepancy between nominal resolution and practically achievable feature size. For example, Fee et al. noted that the resolution of their printer was $28 \mu \mathrm{m}$, but the desired geometries could only reliably be produced at an order of magnitude larger [19]. Nawada et al. used the same printer to produce particles with a diameter of roughly $400 \mu \mathrm{m}$, and observed striations ranging from 25 to $32 \mu \mathrm{m}$ in size as a result of the 3D-printer's layering process [91]. These imperfections are a potential source of local inhomogeneity. In perspective, to obtain sub-2- $\mu$ m particles through 3D-printing methods, a technology with nominal resolution in the order of $100 \mathrm{~nm}$ or less would be required. While TPP can achieve such resolution levels, unreasonably long printing times (months if not years!) would be required to manufacture a full-scale column using such high-resolution methods. Despite the current speed and resolution limitations, work in this area is providing a solid proof-of-concept base to revolutionise chromatographic operations in the near future.

\section{Materials}

Materials suitable for chromatographic operations are inherently porous, with small diffusional pores in the range of the tens of nanometers. While this range of characteristic dimensions is out of the reach of 3D printing technologies (and most likely will be so in the near future), it is paramount that printed chromatography media maintain highly porous characteristics, displaying large surface areas to maximise interaction with the analytes and thus enable high separation capacities. In addition, the material must have excellent mechanical properties to withstand the high pressures typical of HPLC and UHPLC operations, a particularly challenging task for porous materials [132].

The compatibility of materials that can be processed by 3D printers and their suitability for chromatographic operations is another challenge to consider. 3D printing technologies have greatly evolved, allowing the creation of complex shapes with a range of materials including metals, ceramics, polymers, and hydrogels. Some of these materials, e.g., silica, hydroxyapatite, acrylates, methacrylates, agarose, and cellulose, are currently employed in chromatography columns too $[29,132,133]$. While a partial crossover of materials between 3D printing and chromatography does exist, in reality, a number of constraints limit the immediate transfer of standard $3 \mathrm{D}$ printing techniques and materials to 
the chromatography field. For example, while chromatographers are interested in porous materials, the 3D printing industry tends to produce "dense parts", common terminology in the 3D printing community to describe objects with minimal void fraction and greater mechanical properties. This issue could be solved, for example, by the development of new 3D printable material formulations that include appropriate porogens or pore formers. Porogenic solvents such as water, alcohols (e.g., methanol, ethanol, 1-propanol, 2-propanol, 1,4-butanediol, dodecanol, cyclohexanol), dimethyl sulfoxide, and polyethylene glycol (PEG), have already been successfully employed in the preparation of monolithic stationary phases in liquid chromatography [134-138]. An approach to the manufacture of ordered stationary phases is a three-step process referred as to "negative templating" [139]. In the first step, standard 3D printers and materials are employed to produce moulds (i.e., negative templates) having appropriate morphology. In the second step, the mould is infused with the chromatographic material, while, in the last step, the original mould is dissolved through the use of appropriate solvents (e.g., acetone if printing with ABS-based materials, water if printing with polyvinyl alcohol, or organic oils if printing with wax-based materials). While this approach successfully leads to a stationary phase with desired three-dimensional morphology and appropriate material for chromatographic operations, its multi-step procedure requires long manufacturing times and adds complexity, hence conflicting with industrial priorities.

Development of materials compatible with 3D printing techniques and chromatographic operations is strategically important for the other practical and more important reasons. Materials employed in 3D printers are often proprietary and with undisclosed composition, containing an uncertain number of additives, fillers, plasticisers, and other components which might interact unpredictably during activation and functionalisation procedures and ultimately interfere with chromatographic operations. Worthy of mention is the serendipitous result obtained by MacDonald and co-workers, who employed a polyjet 3D printer and a photopolymerisable material to create a thin-layer chromatography device without the need to modify the stationary phase [110]. The separation was obtained thanks to the functional groups already present in the various components making up the formulation, even though its composition is proprietary and only guessed by the authors through IR analysis. Unfortunately, further work is highly constrained by the lack of knowledge of the material formulation, preventing optimisation and fine tuning of the material to improve separation performance. Knowledge of the material employed is even more important for applications in downstream processing, where exact characterisation of the materials employed in the manufacturing process is required to obtain FDA approval, including full analysis of extractables and leachables [140]. To solve this issue, ex-novo development of new material formulations is required. While this approach opens new opportunities for both the 3D printing and the chromatography industries, the uncertainties associated with compatibility issues and the long times required for material development, including the warrant of appropriate mechanical properties, seem to discourage current research. Simon and Dimartino have recently reported a novel method for direct 3D printing of functional monolithic adsorbents for chromatography in one simple step [141]. The concept proposed is based on the controlled polymerisation (through a digital light processing $3 \mathrm{D}$ printer) of bifunctional monomers bearing on one side the functional ligand, and, on the other end, a chemical group that can take part in the polymerisation reaction. To prove the concept, a strong anion exchange adsorber was directly $3 \mathrm{D}$ printed and tested for the separation of test model proteins (BSA) as well as proteins contained in cell culture supernatants. This approach does not only addresses the existing challenge of material compatibility between 3D printing and chromatographic operations, but also removes the traditional functionalisation steps currently carried out in the industry to produce chromatographically active stationary phases.

\section{Design}

The fabrication of columns by AM has potential to move away from the traditional particle-based beds and enables novel ideas and approaches to the design of homogeneous stationary phases with superior properties. The geometrical properties of the bed, e.g., porosity, surface area, and tortuosity, can be tuned at one's will, allowing the production of columns specialised to suit specific applications in the separation sciences. Thanks to the layer-by-layer fabrication process, 3D printing can create extremely complex model geometries with no additional effort or cost than printing a simple cube. This enables the shift from the conventional "packed" beds to "3D printed monolithic" beds, whose design is optimised for the improved mechanical strength, structural uniformity, and pressure-drop characteristics [118].

Salloum and Robinson studied in silico the mass transport properties in a monolithic geometry for use in gas chromatography [142]. The unit cell, defined as the struts along the edges of a cube, was periodically repeated in the 3D space to obtain a macroscopic structure. The authors observed that such morphology performs better when oriented in the [111] axis with respect to the main direction of the flow. They also noticed that their 3D lattice geometry had superior HETP with respect to a bundle of parallel tubes, mostly thanks to the frequent mixing between flow paths. These conclusions match those presented by Dolamore et al. for spherical particles [94]. 

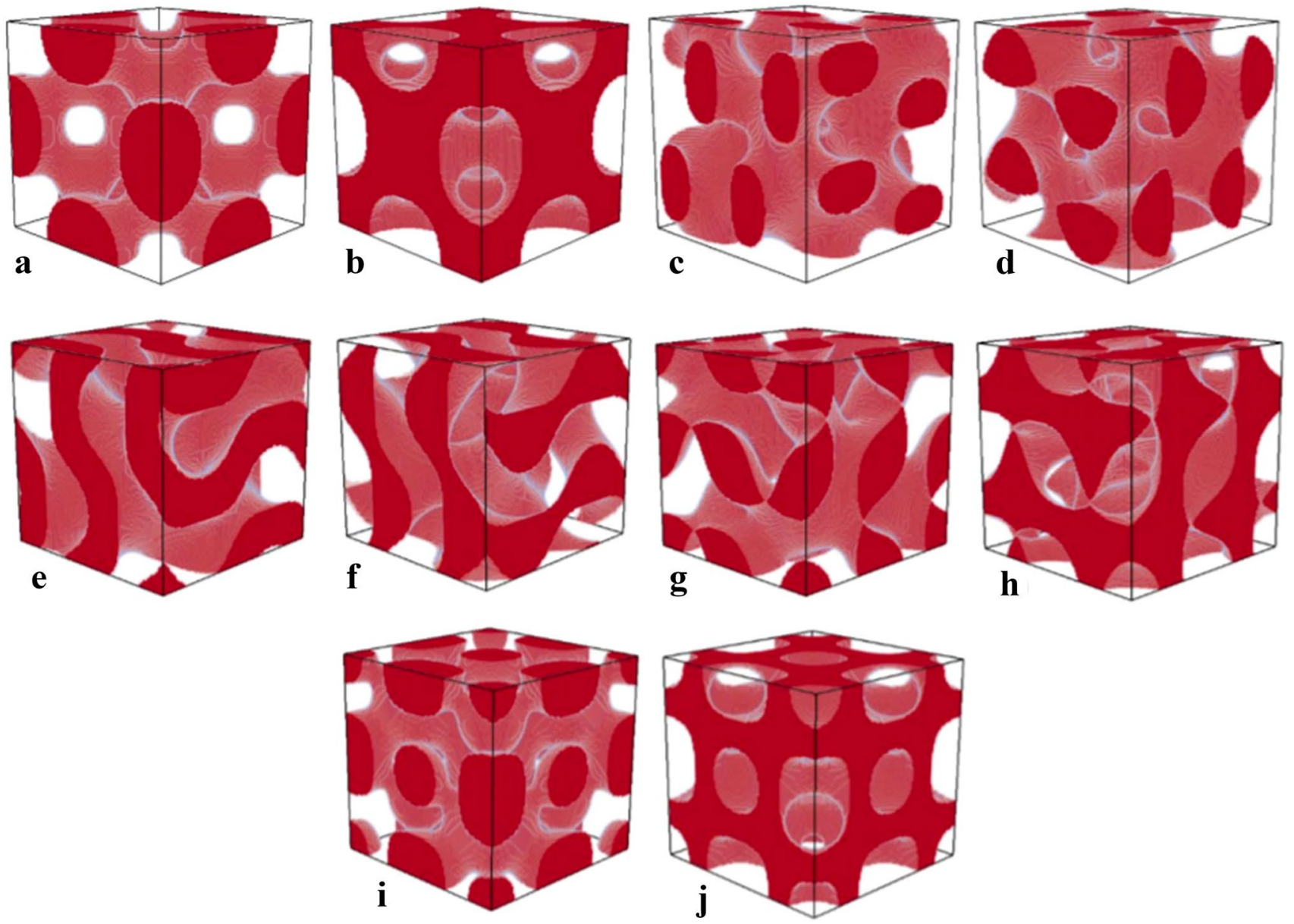

Fig. 15 Illustrations of various TPMS. Permutations of F-RD represented by $\mathbf{a}$ and $\mathbf{b}$ P2-GD by $\mathbf{c}, \mathbf{d}$ Double Gyroid by $\mathbf{e}, \mathbf{f}$ L by $\mathbf{g}, \mathbf{h}$ and D' by $\mathbf{i}$, j. Reprinted with permission from [147]

Bicontinuous cubic structures and TPMS are other examples of complex but ordered geometries that could benefit chromatography (Fig. 15). These morphologies are relatively easily described by mathematical expressions, but are virtually impossible to fabricate using the conventional manufacturing techniques. TPMS produce structurally strong periodic packing with interconnected flow paths having minimal flow resistance [143], all desirable qualities of a chromatographic packing. A wide variety of TPMS exist, such as the Schwarz Primitive, Schoen Gyroid and Schwarz Diamond, all of which can be represented mathematically and 3D printed as monoliths. For example, the gyroid geometry (Fig. 15f) enables uniform distribution of internal stresses in a controlled manner, thus avoiding localised regions of stress overload from which cracks could form and propagate, eventually causing the disruption and crushing of the porous stationary phase [144-146].

Fee et al. 3D printed agarose columns based on the gyroidal geometry, one of the TPMS, and employed them for chromatographic operations (Fig. 16) [139]. The material, functionalised with cation exchange groups, retained the positively charged cytochrome $\mathrm{C}$ protein (at neutral $\mathrm{pH}$ ), while the negatively charged BSA protein and whole Saccharomices cerevisiae cells did not interact with the $3 \mathrm{D}$ printed column and were recovered in the flowthrough. This work demonstrates that $3 \mathrm{D}$ printing is a viable method to fabricate fully functional chromatographic columns with complex but homogeneous morphology. In addition, it expands the applicability window of chromatographic operations, proving the concept of solid tolerant chromatography media, i.e., stationary phases with wide channels $(300-500 \mu \mathrm{m})$ that enable the processing of feedstocks containing solid particles (e.g., cells, cell debris, and aggregates) without the risk of compromising the column characteristics (e.g., column clogging).

In his Ph.D. thesis, Dolamore investigated the chromatographic performance of a number of 3D morphologies, including TPMS, using the Lattice Boltzmann modelling approach [147]. He concluded that TPMS exhibit smaller HETP than any arrangement of spherical particles, mainly 


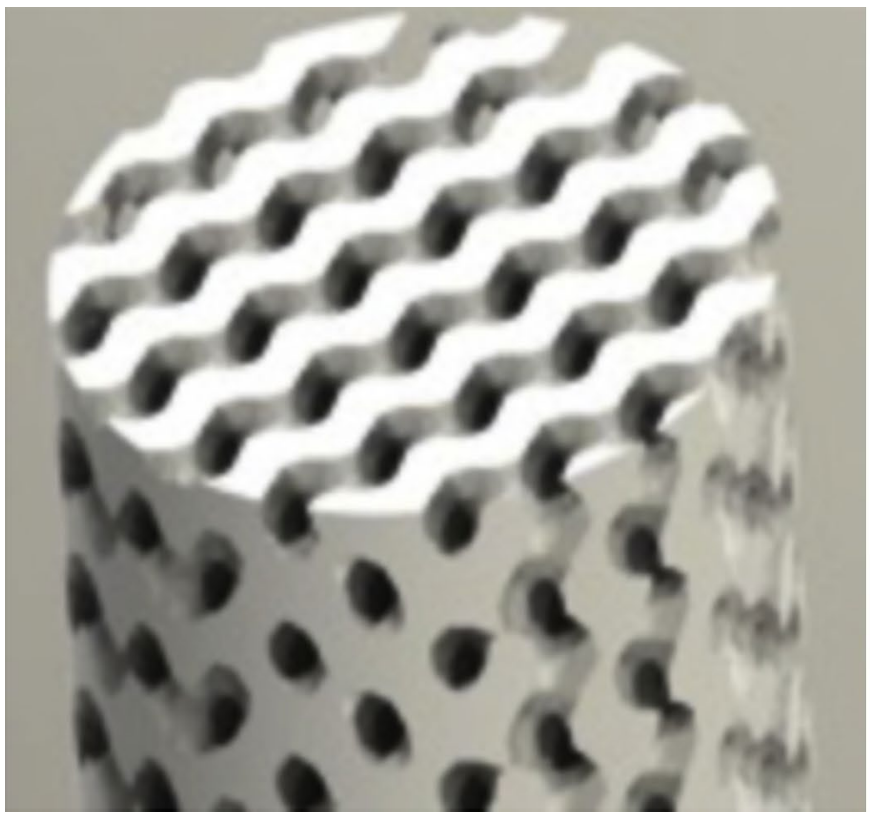

Fig. 16 Left: CAD design of TPMS monolith modelled on the Schoen Gyroid. Reprinted with permission from [116]. Right: 3D printed TPMS stationary phase in a chromatographic column. The column, bearing cation exchange functionalities, was overloaded with a mix-

because of the greater uniformity of the flow channels within the monolith compared to spherical packings. These results promise an imminent revolution in the chromatography arena through additive manufacturing. Yet, the choice of cuboidal or gyroidal geometries is relatively empirical, and more modelling and experimental work is required to eventually identify the "ideal" column morphology for chromatographic operations.

\section{Concluding Remarks}

20 years ago, in 1998, the group of Regnier proposed the idea of pillar-array micromachined columns (Fig. 1), demonstrating, for the first time, the manufacture of fully homogeneous stationary phases [35]. In the following years, a series of experimental and computational works consistently evidenced far superior chromatographic performance of ordered homogeneous beds over randomly packed columns, e.g., reduced plate heights as low as 0.5 and very-lowpressure-drop characteristics.

The literature on this topic is extremely rich on twodimensional pillar-array columns, while studies on threedimensional beds are scarcer. This difference can be credited to past (and current) limitations of the manufacturing methods used to create such column morphologies. Micromachining and photolithography, the two main methods to fabricate two-dimensional columns, were available

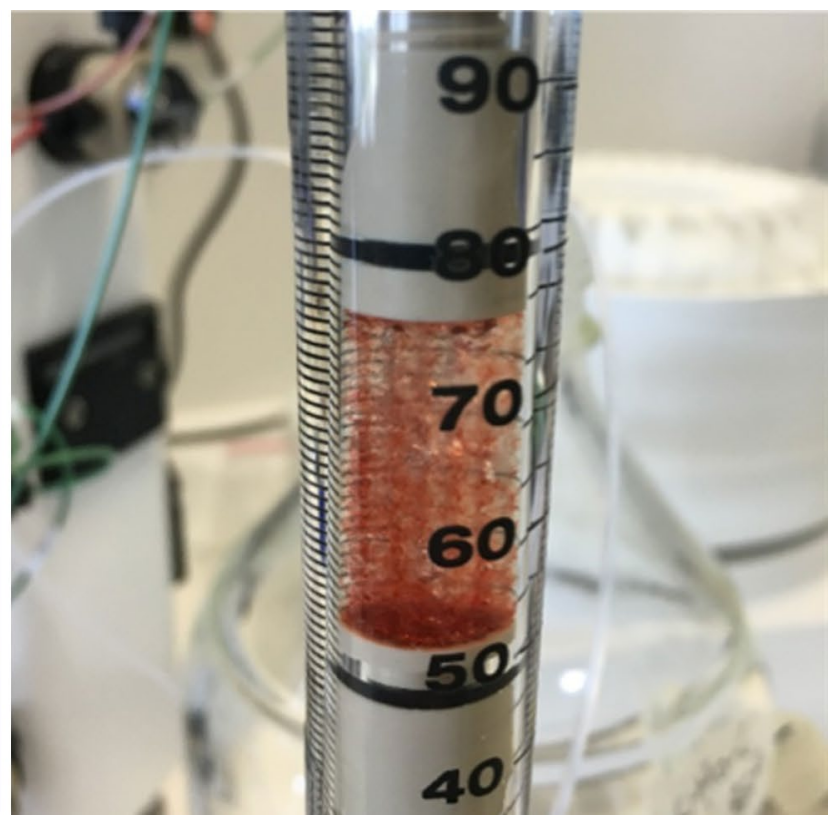

ture of BSA, cytochrome C, and whole yeast cells (Sarracomices cerevisiae). Red colour is due to the bound cytochrome C. With permission of [118]

20 years ago, while additive manufacturing, or 3D printing, was unknown to practically all. In the last 10 years, 3D printing has become increasingly affordable and accessible to many, with good compromise between cost and resolution. There is consequently a renewed interest in homogeneous stationary phases that can be fabricated in three dimensions, finally allowing experimental testing of such new particle configurations. The first example of a 3D printed chromatography column was presented by Fee et al. in 2014 with packed beds designed in simple cubic arrangement of spherical particles [19], a study which also demonstrated the 3D printing of ancillary elements such as connectors, flow distributors, and column walls together with the stationary phase.

Since then, a series of experimental and computational studies have been published, considering various morphological features of the bed such as particle arrangement, shape, and alignment, and all confirming the anticipated advantages of homogeneous stationary phases over their random counterpart. It must be noted here that the concept of a packed bed is practically lost in 3D printed columns. In fact, additive manufacturing is not limited by the complexity of the design, and more efficient beds based on regular monolithic architectures (e.g., TPMS) have already been reported. Customisability, another advantage of additive manufacturing, opens the opportunity to design and create bespoke stationary phases to perfectly suit specific applications, both in the analytical and downstream fields. 
Computational methods currently are the best tool to harness this opportunity, allowing rapid and inexpensive optimisation of the stationary-phase geometry.

Beyond the chromatographic bed, additive manufacturing also enables new designs for the column cartridge, with the possibility of miniaturising extremely long columns in microchip formats, or to integrate several columns in the same $3 \mathrm{D}$ printed device for, e.g., $\mathrm{LC} \times \mathrm{LC} \times \mathrm{LC}$. In the future, smart designs for injectors, valves, detectors, etc., might benefit from fabrication and integration within a 3D printed column.

Yet, some key challenges must be addressed to make 3D printing and chromatography truly compatible. First, new additive manufacturing methods should be developed to allow fabrication of columns of reasonable size, at a reasonable speed, and at a desired resolution - where the "reasonable" adjective depends on application, e.g., analytical versus downstream processing. The development of materials compatible with both 3D printing and chromatography operations is another fertile area of growth. In fact, most of the materials in today's $3 \mathrm{D}$ printing arena have proprietary formulations, hindering any material optimisation effort. To overcome this barrier, further porous materials with appropriate chemistry for chromatography and appropriate physical properties for 3D printing should be developed.

It is expected that future improvements in additive manufacturing and computational tools will allow the design and fabrication of highly efficient and specialised columns at low cost, heralding the next generation of packed-bed technology.

\section{Compliance with ethical standards}

Conflict of interest The authors declare that they have no conflicts of interest.

Open Access This article is distributed under the terms of the Creative Commons Attribution 4.0 International License (http://creativeco mmons.org/licenses/by/4.0/), which permits unrestricted use, distribution, and reproduction in any medium, provided you give appropriate credit to the original author(s) and the source, provide a link to the Creative Commons license, and indicate if changes were made.

\section{References}

1. Kolev N (2006) Packed bed columns: for absorption, desorption, rectification and direct heat transfer. Elsevier, Amsterdam

2. Patel DC, Wahab MF, Armstrong DW, Breitbach ZS (2016) Advances in high-throughput and high-efficiency chiral liquid chromatographic separations. J Chromatogr A 1467:2-18

3. Knox JH, Saleem M (1969) Kinetic conditions for optimum speed and resolution in column chromatography. J Chromatogr Sci 7:614-622
4. Snyder LR (2000) HPLC: past and present. Anal Chem 72:412-420

5. Nguyen DT-T, Guillarme D, Rudaz S, Veuthey J-L (2006) Fast analysis in liquid chromatography using small particle size and high pressure. J Sep Sci 29:1836-1848

6. De Vos J, Broeckhoven K, Eeltink S (2016) Advances in ultrahigh-pressure liquid chromatography technology and system design. Anal Chem 88:262-278

7. Svec F, Lv Y (2014) Advances and recent trends in the field of monolithic columns for chromatography. Anal Chem 87:250-273

8. Wahab MF, Patel DC, Wimalasinghe RM, Armstrong DW (2017) Fundamental and practical insights on the packing of modern high-efficiency analytical and capillary columns. Anal Chem 89:8177-8191

9. Smits W, Deridder S, Desmet G (2014) The impact of flow distribution on column performance: a computational fluid dynamics study. J Chromatogr A 1369:125-130

10. Billen J, Desmet G (2007) Understanding and design of existing and future chromatographic support formats. J Chromatogr A 1168:73-99

11. Li L, Yan X, Yang J, Wang Q (2015) Computational study of chromatography performance in ordered packed beds with spherical or ellipsoidal particles. Energy Procedia 75:3322-3327

12. Horváth K, Lukács D, Sepsey A, Felinger A (2014) Effect of particle size distribution on the separation efficiency in liquid chromatography. J Chromatogr A 1361:203-208

13. Gzil P, De Smet J, Desmet G (2006) A discussion of the possible ways to improve the performance of silica monoliths using a kinetic plot analysis of experimental and computational plate height data. J Sep Sci 29:1675-1685

14. Op De Beeck J, De Malsche W, De Moor P, Desmet G (2012) Hydrodynamic chromatography separations in micro- and nanopillar arrays produced using deep-UV lithography. J Sep Sci 35:1877-1883

15. Eghbali H, Verdoold V, Vankeerberghen L, Gardeniers H, Desmet $\mathrm{G}$ (2009) Experimental investigation of the band broadening arising from short-range interchannel heterogeneities in chromatographic beds under the condition of identical external porosity. Anal Chem 81:705-715

16. Schure MR, Maier RS (2006) How does column packing microstructure affect column efficiency in liquid chromatography? J Chromatogr A 1126:58-69

17. Daneyko A, Hoelzel A, Khirevich S, Tallarek U (2011) Influence of the particle size distribution on hydraulic permeability and eddy dispersion in bulk packings. Anal Chem 83:3903-3910

18. Low ZX, Chua YT, Ray BM, Mattia D, Metcalfe IS, Patterson DA (2017) Perspective on 3D printing of separation membranes and comparison to related unconventional fabrication techniques. J Memb Sci 523:596-613

19. Fee C, Nawada S, Dimartino S (2014) 3D printed porous media columns with fine control of column packing morphology. $\mathrm{J}$ Chromatogr A 1333:18-24

20. Sandron S, Heery B, Gupta V, Collins D, Nesterenko EP, Nesterenko PN, Talebi M, Beirne S, Thompson F, Wallace GG, Brabazon D, Regan F, Paull B (2014) 3D printed metal columns for capillary liquid chromatography. Analyst 139:6343-6347

21. Gupta V, Talebi M, Deverell J, Sandron S, Nesterenko PN, Heery B, Thompson F, Beirne S, Wallace GG, Paull B (2016) 3D printed titanium micro-bore columns containing polymer monoliths for reversed-phase liquid chromatography. Anal Chim Acta 910:84-94

22. Couck S, Lefevere J, Mullens S, Protasova L, Meynen V, Desmet G, Baron GV, Denayer JFM (2017) $\mathrm{CO}_{2}, \mathrm{CH}_{4}$ and $\mathrm{N}_{2}$ separation with a 3DFD-printed ZSM-5 monolith. Chem Eng J 308:719-726 
23. Femmer T, Flack I, Wessling M (2016) Additive manufacturing in fluid process engineering. Chem Ing Tech 88:535-552

24. Farahani RD, Dubé M, Therriault D (2016) Three-dimensional printing of multifunctional nanocomposites: manufacturing techniques and applications. Adv Mater 28:5794-5821

25. Harun WSW, Kamariah MSIN, Muhamad N, Ghani SAC, Ahmad F, Mohamed Z (2018) A review of powder additive manufacturing processes for metallic biomaterials. Powder Technol 327:128-151

26. Ngo TD, Kashani A, Imbalzano G, Nguyen KTQ, Hui D (2018) Additive manufacturing (3D printing): a review of materials, methods, applications and challenges. Compos Part B Eng 143:172-196

27. Desmet G, Eeltink S (2013) Fundamentals for LC miniaturization. Anal Chem 85:543-556

28. Yuan X, Oleschuk RD (2018) Advances in microchip liquid chromatography. Anal Chem 90:283-301

29. Haghighi F, Talebpour Z, Nezhad AS (2018) Towards fully integrated liquid chromatography on a chip: evolution and evaluation. TrAC Trends Anal Chem 105:302-337

30. De Malsche W, Eghbali H, Clicq D, Vangelooven J, Gardeniers H, Desmet G (2007) Pressure-driven reverse-phase liquid chromatography separations in ordered nonporous pillar array columns. Anal Chem 79:5915-5926

31. van Deemter JJ, Zuiderweg FJ, Klinkenberg A (1956) Longitudinal diffusion and resistance to mass transfer as causes of nonideality in chromatography. Chem Eng ScL 5:3867

32. Knox JH (1999) Band dispersion in chromatography-a new view of A -term dispersion. J Chromatogr A 831:3-15

33. Knox JH (2002) Band dispersion in chromatography - a universal expression for the contribution from the mobile zone. J Chromatogr A 960:7-18

34. Schweiger S, Hinterberger S, Jungbauer A (2017) Column-tocolumn packing variation of disposable pre-packed columns for protein chromatography. J Chromatogr A 1527:70-79

35. He B, Tait N, Regnier F (1998) Fabrication of nanocolumns for liquid chromatography. Anal Chem 70:3790-3797

36. Regnier FE (2000) Microfabricated monolith columns for liquid chromatography: sculpting supports for liquid chromatography. HRC J High Resolut Chromatogr 23:19-26

37. Op De Beeck J, Callewaert M, Ottevaere H, Gardeniers H, Desmet G, De Malsche W (2013) On the advantages of radially elongated structures in microchip-based liquid chromatography. Anal Chem 85:5207-5212

38. De Smet J, Gzil P, Vervoort M, Verelst H, Baron GV, Desmet G (2004) Influence of the pillar shape on the band broadening and the separation impedance of perfectly ordered 2-D porous chromatographic media. Anal Chem 76:3716-3726

39. De Malsche W, Gardeniers H, Desmet G (2008) Experimental study of porous silicon shell pillars under retentive conditions. Anal Chem 80:5391-5400

40. De Malsche W, Op De Beeck J, De Bruyne S, Gardeniers H, Desmet G (2012) Realization of $1 \times 10^{6}$ theoretical plates in liquid chromatography using very long pillar array columns. Anal Chem 84:1214-1219

41. Detobel F, Eghbali H, De Bruyne S, Terryn H, Gardeniers H, Desmet G (2009) Effect of the presence of an ordered micropillar array on the formation of silica monoliths. J Chromatogr A 1216:7360-7367

42. Detobel F, De Bruyne S, Vangelooven J, De Malsche W, Aerts T, Terryn H, Gardeniers H, Eeltink S, Desmet G (2010) Fabrication and chromatographic performance of porous-shell pillar-array columns. Anal Chem 82:7208-7217

43. Billen J, Gzil P, Vervoort N, Baron GV, Desmet G (2005) Influence of the packing heterogeneity on the performance of liquid chromatography supports. J Chromatogr A 1073:53-61
44. Grinias JP, Kennedy RT (2016) Advances in and prospects of microchip liquid chromatography. TrAC Trends Anal Chem $81: 110-117$

45. Op De Beeck J, Callewaert M, Ottevaere H, Gardeniers H, Desmet G, De Malsche W (2014) Suppression of the sidewall effect in pillar array columns with radially elongated pillars. J Chromatogr A 1367:118-122

46. Giddings JC (1960) Coiled columns and resolution in gas chromatography. J Chromatogr A 3:520-523

47. Callewaert M, De Malsche W, Ottevaere H, Thienpont H, Desmet $G$ (2014) Assessment and numerical search for minimal tayloraris dispersion in micro-machined channels of nearly rectangular cross-section. J Chromatogr A 1368:70-81

48. Schisla DK, Ding H, Cam PW, Cussler EL (1993) Polydisperse tube diameters compromise multiple open tubular chromatography. Separations 39:946-953

49. Gzil P, Baron GV, Desmet G (2003) Computational fluid dynamics simulations yielding guidelines for the ideal internal structure of monolithic liquid chromatography columns. J Chromatogr A 991:169-188

50. Maikin DS, Wel B, Fogiel AJ, Staats SL, Wirth MJ (2010) Submicrometer plate heights for capillaries packed with silica colloidal crystals. Anal Chem 82:2175-2177

51. Wei B, Rogers BJ, Wirth MJ (2012) Slip-flow in colloidal crystals for ultra-efficient chromatography. J Am Chem Soc 134:10780-10782

52. Yan X, Wang Q (2013) Numerical investigation into the effects of ordered particle packing and slip flow on the performance of chromatography. J Sep Sci 36:1524-1529

53. Wu Z, Rogers BJ, Wei B, Wirth MJ (2013) Insights from theory and experiments on slip flow in chromatography. J Sep Sci 36:1871-1876

54. Schenker I, Filser FT, Gauckler LJ, Aste T, Herrmann HJ (2009) Quantification of the heterogeneity of particle packings. Phys Rev E Stat Nonlinear Soft Mater Phys 80:1-9

55. Khirevich S, Daneyko A, Hoeltzel A, Seidel-Morgenstern A, Tallarek U (2010) Statistical analysis of packed beds, the origin of short-range disorder, and its impact on eddy dispersion. J Chromatogr A 1217:4713-4722

56. Roblee LHS, Baird RM, Tierney W (1958) Radial porosity variations in packed beds. AIChE J 4:460-464

57. Yun T, Guiochon G (1996) Modeling of radial heterogeneity in chromatographic columns II. Separation of a two-component mixture on a column with cylindrical symmetry. J Chromatogr A 734:97-103

58. Yun T, Guiochon G (1997) Visualization of the heterogeneity of column beds. J Chromatogr A 760:17-24

59. Daneyko A, Khirevich S, Höltzel A, Seidel-morgenstern A, Tallarek U (2011) From random sphere packings to regular pillar arrays: effect of the macroscopic confinement on hydrodynamic dispersion. J Chromatogr A 1218:8231-8248

60. Khirevich S, Höltzel A, Tallarek U (2011) Transient and asymptotic dispersion in confined sphere packings with cylindrical and non-cylindrical conduit geometries. Philos Trans A Math Phys Eng Sci 369:2485-2493

61. Vangelooven J, Desmet G (2010) Theoretical optimisation of the side-wall of micropillar array columns using computational fluid dynamics. J Chromatogr A 1217:8121-8126

62. Maier RS, Kroll DM, Bernard RS, Howington SE, Peters JF, Davis HT (2003) Hydrodynamic dispersion in confined packed beds. Phys Fluids 15:3795-3815

63. Reising AE, Schlabach S, Baranau V, Stoeckel D, Tallarek U (2017) Analysis of packing microstructure and wall effects in a narrow-bore ultrahigh pressure liquid chromatography column using focused ion-beam scanning electron microscopy. J Chromatogr A 1513:172-182 
64. Gritti F (2018) On the relationship between radial structure heterogeneities and efficiency of chromatographic columns. J Chromatogr A 1533:112-126

65. Bruns S, Grinias JP, Blue LE, Jorgenson JW, Tallarek U (2012) Morphology and separation efficiency of low-aspect-ratio capillary ultrahigh pressure liquid chromatography columns. Anal Chem 84:4496-4503

66. Aggarwal P, Asthana V, Lawson JS, Tolley HD, Wheeler DR, Mazzeo BA, Lee ML (2014) Correlation of chromatographic performance with morphological features of organic polymer monoliths. J Chromatogr A 1334:20-29

67. Vervoort N, Billen J, Gzil P, Baron GV, Desmet G (2004) Importance and reduction of the sidewall-induced band-broadening effect in pressure-driven microfabricated columns. Anal Chem 76:4501-4507

68. Liekens A, Billen J, Sherant R, Ritchie H, Denayer J, Desmet G (2011) High performance liquid chromatography column packings with deliberately broadened particle size distribution: relation between column performance and packing structure. $\mathbf{J}$ Chromatogr A 1218:6654-6662

69. Svec F (2010) New developments in the field of monoliths for chromatography. LC GC Eur 23:1-11

70. Boi C, Dimartino S (2016) Advances in membrane chromatography for the capture step of monoclonal antibodies. Curr Org Chem 21(17):1753-1759

71. Randunu KM, Dimartino S, Marcus RK (2012) Dynamic evaluation of polypropylene capillary-channeled fibers as a stationary phase in high-performance liquid chromatography. J Sep Sci 35:3270-3280

72. Tanaka N, Nagayama H, Kobayashi H, Ikegami T, Hosoya K, Ishizuka N, Minakuchi H, Nakanishi K, Cabrera K, Lubda D (2000) Monolithic silica columns for HPLC, micro-HPLC, and CEC. HRC J High Resolut Chromatogr 23:111-116

73. Gritti F, Guiochon G (2009) Mass transfer kinetic mechanism in monolithic columns and application to the characterization of new research monolithic samples with different average pore sizes. J Chromatogr A 1216:4752-4767

74. Hormann K, Müllner T, Bruns S, Höltzel A, Tallarek U (2012) Morphology and separation efficiency of a new generation of analytical silica monoliths. J Chromatogr A 1222:46-58

75. Vonk RJ, Vaast A, Eeltink S, Schoenmakers PJ (2014) Titaniumscaffolded organic-monolithic stationary phases for ultra-highpressure liquid chromatography. J Chromatogr A 1359:162-169

76. Vervoort N, Saito H, Nakanishi K, Desmet G (2005) Experimental validation of the tetrahedral skeleton model pressure drop correlation for silica monoliths and the influence of column heterogeneity. Anal Chem 77:3986-3992

77. Stoeckel D, Koebel C, Loeh MO, Smarsly BM, Tallarek U (2015) Morphological analysis of physically reconstructed silica monoliths with submicrometer macropores: effect of decreasing domain size on structural homogeneity. Langmuir 31:7391-7400

78. Przybycien TM, Pujar NS, Steele LM (2004) Alternative bioseparation operations: life beyond packed-bed chromatography. Curr Opin Biotechnol 15:469-478

79. Jungreuthmayer C, Steppert P, Sekot G, Zankel A, Reingruber H, Zanghellini J, Jungbauer A (2015) The 3D pore structure and fluid dynamics simulation of macroporous monoliths: high permeability due to alternating channel width. J Chromatogr A 1425:141-149

80. Vervoort N, Gzil P, Baron GV, Desmet G (2003) A correlation for the pressure drop in monolithic silica columns. Anal Chem 75:843-850

81. Vervoort N, Gzil P, Baron GV, Desmet G (2004) Model column structure for the analysis of the flow and band-broadening characteristics of silica monoliths. J Chromatogr A 1030:177-186
82. Snyder LR (1969) Column efficiencies in liquid adsorption chromatography: past, present and future. J Chromatogr Sci 7:352-360

83. Lottes F, Arlt W, Minceva M, Stenby EH (2009) Hydrodynamic impact of particle shape in slurry packed liquid chromatography columns. J Chromatogr A 1216:5687-5695

84. Gzil P, De Smet J, Vervoort N, Verelst H, Baron GV, Desmet $G$ (2004) Computational study of the band broadening in twodimensional etched packed bed columns for on-chip high-performance liquid chromatography. J Chromatogr A 1030:53-62

85. De Smet J, Gzil P, Vervoort N, Verelst H, Baron GV, Desmet G (2005) On the optimisation of the bed porosity and the particle shape of ordered chromatographic separation media. J Chromatogr A 1073:43-51

86. Futagami S, Hara T, Ottevaere H, Baron GV, Desmet G, Malsche W De (2017) Preparation and evaluation of mesoporous silica layers on radially elongated pillars. J Chromatogr A 1523:234-241

87. Sandra K, Vandenbussche J, Vandenheede I, Claerebout B, Op De Beeck J, Jacobs P, De Malsche W, Desmet G, Sanra P (2018) Peptide mapping of monoclonal antibodies and antibody - drug conjugates using micro-pillar array columns combined with mass spectrometry. LCGC Eur 31:155-166

88. Nawada S, Dimartino S, Fee C (2014) The effects of bead overlap on performance of 3D printed packed bed columns. International Labmate April

89. Yang J, Wang Q, Zeng M, Nakayama A (2010) Computational study of forced convective heat transfer in structured packed beds with spherical or ellipsoidal particles. Chem Eng Sci 65:726-738

90. Li L, Yan X, Yang J, Wang Q (2016) Numerical investigation on band-broadening characteristics of an ordered packed bed with novel particles. Appl Energy. https://doi.org/10.1016/j.apene rgy.2016.03.045

91. Nawada S, Dimartino S, Fee C (2017) Dispersion behavior of 3D-printed columns with homogeneous microstructures comprising differing element shapes. Chem Eng Sci 164:90-98

92. Hlushkou D, Bruns S, Tallarek U (2010) High-performance computing of flow and transport in physically reconstructed silica monoliths. J Chromatogr A 1217:3674-3682

93. Schure MR, Maier RS, Kroll DM, Davis HT (2004) Simulation of ordered packed beds in chromatography. J Chromatogr A 1031:79-86

94. Dolamore F, Fee C, Dimartino S (2018) Modelling ordered packed beds of spheres: the importance of bed orientation and the influence of tortuosity on dispersion. J Chromatogr A 1532:150-160

95. Mitulović G (2015) New HPLC techniques for proteomics analysis: a short overview of latest developments new HPLC techniques for proteomics analysis : a short overview of latest developments. J Chromatogr Relat Technol 38:390-403

96. Davydova E, Schoenmakers PJ, Vivó-truyols G (2013) Study on the performance of different types of three-dimensional chromatographic systems. J Chromatogr A 1271:137-143

97. Reichmuth DS, Shepodd TJ, Kirby BJ (2005) Microchip HPLC of peptides and proteins. Anal Chem 77:2997-3000

98. Ehlert S, Kraiczek K, Mora JA, Dittmann M, Rozing GP, Tallarek U (2008) Separation efficiency of particle-packed HPLC microchips. Anal Chem 80:5945-5950

99. Aoyama C, Saeki A, Noguchi M, Shirasaki Y, Shoji S, Funatsu T, Mizuno J, Tsunoda M (2010) Use of folded micromachined pillar array column with low-dispersion turns for pressure-driven liquid chromatography. Anal Chem 82:1420-1426

100. Culbertson CT, Jacobson SC, Ramsey JM (1998) Dispersion sources for compact geometries on microchips. Anal Chem 70:3781-3789 
101. Griffiths SK, Nilson RH (2001) Low-dispersion turns and junctions for microchannel systems. Anal Chem 73:272-278

102. Song Y, Takatsuki K, Isokawa M, Sekiguchi T, Mizuno J, Funatsu T, Shoji S, Tsunoda M (2013) Fast and quantitative analysis of branched-chain amino acids in biological samples using a pillar array column amino acid analysis. Anal Bioanal Chem 405:7993-7999

103. Gupta V, Beirne S, Nesterenko PN, Paull B (2018) Investigating the effect of column geometry on separation efficiency using 3D printed liquid chromatographic columns containing polymer monolithic phases. Anal Chem 90:1186-1194

104. Gilar M, McDonald TS, Gritti F, Roman GT, Johnson JS, Bunner B, Michienzi JD, Collamati RA, Murphy JP, Satpute DD, Bannon MP, DellaRovere D, Jencks RA, Dourdeville TA, Fadgen KE, Gerhardt GC (2018) Chromatographic performance of microfluidic liquid chromatography devices: experimental evaluation of straight versus serpentine packed channels. J Chromatogr A 1533:127-135

105. Gritti F, Martin M, Guiochon G (2009) Influence of viscous friction heating on the efficiency of columns operated under very high pressures. Anal Chem 81:3365-3384

106. Tyers M, Mann M (2003) From genomics to proteomics. Nature 422:193-197

107. Wouters B, Davydova E, Wouters S, Vivo-Truyols G, Schoenmakers PJ, Eeltink S (2015) Towards ultra-high peak capacities and peak-production rates using spatial three-dimensional liquid chromatography. Lab Chip 15:4415-4422

108. Adamopoulou T, Deridder S, Desmet G, Schoenmakers PJ (2018) Two-dimensional insertable separation tool (TWIST) for flow confinement in spatial separations. J Chromatogr A 1577:120-123

109. Kalsoom U, Nesterenko PN, Paull B (2018) Current and future impact of 3D printing on the separation sciences. TrAC Trends Anal Chem 105:492-502

110. Macdonald NP, Currivan SA, Tedone L, Paull B (2017) Direct production of microstructured surfaces for planar chromatography using 3D printing. Anal Chem 89:2457-2463

111. Fichou D, Morlock GE (2017) Open-source-based 3D printing of thin silica gel layers in planar chromatography. Anal Chem 89:2116-2122

112. Lucklum F, Janssen S, Lang W, Vellekoop MJ (2015) Miniature $3 \mathrm{D}$ gas chromatography columns with integrated fluidic connectors using high-resolution stereolithography fabrication. Procedia Eng 120:703-706

113. Zaidi NA, Tahir MW, Vellekoop MJ, Lang W (2017) A gas chromatographic system for the detection of ethylene gas using ambient air as a carrier gas. Sensors 17:2283

114. Wang H, Cocovi-Solberg DJ, Hu B, Miró M (2017) 3D-printed microflow injection analysis platform for online magnetic nanoparticle sorptive extraction of antimicrobials in biological specimens as a front end to liquid chromatographic assays. Anal Chem 89:12541-12549

115. Gupta V, Mahbub P, Nesterenko PN, Paull B (2018) A new 3D printed radial flow-cell for chemiluminescence detection: application in ion chromatographic determination of hydrogen peroxide in urine and coffee extracts. Anal Chim Acta 1005:81-92

116. Salentijn GI, Permentier HP, Verpoorte E (2014) 3D-printed paper spray ionization cartridge with fast wetting and continuous solvent supply features. Anal Chem 86:11657-11665

117. Wang MM, Laborda P, Conway LP, Duan XC, Huang K, Liu L, Voglmeir J (2016) An integrated 3D-printed platform for the automated isolation of $\mathrm{N}$-glycans. Carbohydr Res 433:14-17

118. Fee C (2017) 3D-printed porous bed structures. Curr Opin Chem Eng 18:10-15
119. Hearn MT (2017) Trends in additive manufacturing of chromatographic and membrane materials. Curr Opin Chem Eng 18:90-98

120. Bikas H, Stavropoulos P, Chryssolouris G (2016) Additive manufacturing methods and modeling approaches: a critical review. Int J Adv Manuf Technol 83:389-405

121. Bahnini I, Rivette M, Rechia A, Siadat A, Elmesbahi A (2018) Additive manufacturing technology: the status, applications, and prospects. Int J Adv Manuf Technol. https://doi.org/10.1007/ s00170-018-1932-y

122. Taboas JM, Maddox RD, Krebsbach PH, Hollister SJ (2003) Indirect solid free form fabrication of local and global porous, biomimetic and composite 3D polymer-ceramic scaffolds. Biomaterials 24:181-194

123. Leukers B, Gülkan H, Irsen SH, Milz S, Tille C, Schieker M, Seitz H (2005) Hydroxyapatite scaffolds for bone tissue engineering made by 3D printing. J Mater Sci Mater Med 16:1121-1124

124. Ko SH, Chung J, Hotz N, Nam KH, Grigoropoulos CP (2010) Metal nanoparticle direct inkjet printing for low-temperature 3D micro metal structure fabrication. J Micromech Microeng 20

125. Derby B (2015) Additive manufacture of ceramics components by inkjet printing. Engineering 1:113-123

126. Limaye AS, Rosen DW (2007) Process planning method for mask projection micro-stereolithography. Rapid Prototyp J $13: 76-84$

127. Sun C, Fang N, Wu DM, Zhang X (2005) Projection micro-stereolithography using digital micro-mirror dynamic mask. Sens Actuators A Phys 121:113-120

128. Juodkazis S, Mizeikis V, Seet KK, Miwa M, Misawa H (2005) Two-photon lithography of nanorods in SU-8 photoresist. Nanotechnology 16:846

129. Sun HB, Kawata S (2004) Two-photon photopolymerization and 3D lithographic microfabrication. Adv Polym Sci 170:169-273

130. Maruo S, Nakamura O, Kawata S (1997) Three-dimensional microfabrication with two-photon-absorbed photopolymerization. Opt Lett 22:132

131. Malinauskas M, Rekštyte S, Lukoševičius L, Butkus S, Balčiunas E, Pečiukaityte M, Baltriukiene D, Bukelskiene V, Butkevičius A, Kucevičius P, Rutkunas V, Juodkazis S (2014) 3D microporous scaffolds manufactured via combination of fused filament fabrication and direct laser writing ablation. Micromachines 5:839-858

132. Müller E, Chung JT, Zhang Z, Sprauer A (2005) Characterization of the mechanical properties of polymeric chromatographic particles by micromanipulation. J Chromatogr A 1097:116-123

133. Wang L, Wei W, Xia Z, Jie X, Xia ZZ (2016) Recent advances in materials for stationary phases of mixed-mode high-performance liquid chromatography. TrAC Trends Anal Chem 80:495-506

134. Hemström P, Nordborg A, Irgum K, Svec F, Fréchet JMJ (2006) Polymer-based monolithic microcolumns for hydrophobic interaction chromatography of proteins. J Sep Sci 29:25-32

135. Peters EC, Petro M, Svec F, Fréchet JMJ (1998) Molded rigid polymer monoliths as separation media for capillary electrochromatography. 1. Fine control of porous properties and surface chemistry. Anal Chem 70:2288-2295

136. Chen X, Tolley HD, Lee ML (2010) Polymeric cation-exchange monolithic columns containing phosphoric acid functional groups for capillary liquid chromatography of peptides and proteins. J Chromatogr A 1217:3844-3854

137. Chen X, Tolley HD, Lee ML (2011) Weak cation-exchange monolithic column for capillary liquid chromatography of peptides and proteins. J Sep Sci 34:2063-2071

138. Li Y, Gu B, Dennis Tolley H, Lee ML (2009) Preparation of polymeric monoliths by copolymerization of acrylate monomers with amine functionalities for anion-exchange capillary liquid chromatography of proteins. J Chromatogr A 1216:5525-5532 
139. Fee C, Dimartino S, Huber T (2017) Separation Medium, WO2017103863A1. https://patents.google.com/patent/WO201 7103863A1/pt. Accessed 24 Sept 2018

140. Markovic I (2007) Evaluation of safety and quality impact of extractable and leachable substances in therapeutic biologic protein products: a risk-based perspective. Expert Opin Drug Saf 6:487-491

141. Simon U, Dimartino S (2018) Direct 3D printing of monolithic ion exchange adsorbers. J Chromatogr A. https://doi. org/10.1016/j.chroma.2018.12.017

142. Salloum M, Robinson DB (2018) A Numerical model of exchange chromatography through 3-D lattice structures. AIChE J 64:1874-1884

143. Guest JK, Prévost JH (2006) Optimizing multifunctional materials: design of microstructures for maximized stiffness and fluid permeability. Int J Solids Struct 43:7028-7047

144. Al-Ketan O, Al-Rub RKA, Rowshan R (2017) Mechanical properties of a new type of architected interpenetrating phase composite materials. Adv Mater Technol 2(2):1600235
145. Maskery I, Sturm L, Aremu AO, Panesar A, Williams CB, Tuck CJ, Wildman RD, Ashcroft IA, Hague RJM (2017) Insights into the mechanical properties of several triply periodic minimal surface lattice structures made by polymer additive manufacturing. Polym (UK). https://doi.org/10.1016/j.polymer.2017.11.049

146. Maskery I, Aboulkhair NT, Aremu AO, Tuck CJ, Ashcroft IA (2017) Compressive failure modes and energy absorption in additively manufactured double gyroid lattices. Addit Manuf $16: 24-29$

147. Dolamore F (2017) In silico analysis of flow and dispersion in ordered porous media. University of Canterbury, Upper Riccarton

Publisher's Note Springer Nature remains neutral with regard to jurisdictional claims in published maps and institutional affiliations. 